\title{
Reproducción en la adolescencia: el caso de Chile y sus implicaciones de política
}

\author{
Jorge Rodriguez $V$.
}

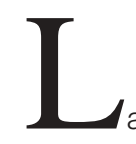

a fecundidad y la maternidad entre las adolescentes preocupan en la región, porque implican adversidades, no han disminuido como en otros grupos etarios y son más frecuentes entre las muchachas pobres. El análisis de los microdatos de los tres últimos censos de Chile muestra además: i) la generalización de un contexto no matrimonial para esta maternidad; ii) el efecto protector de la permanencia en la escuela, que se activa pasado un umbral educativo que se eleva con el tiempo; iii) el protagonismo de los progenitores de las muchachas en cuyos hogares reside la mayor parte de las madres adolescentes, y iv) la necesidad de programas específicos y de intervenciones integrales para reducir la maternidad adolescente, ya que si bien el acceso a información y servicios de salud sexual y reproductiva evita embarazos, es insuficiente cuando faltan oportunidades alternativas a la maternidad o hay cortapisas culturales y sicológicas para usar adecuadamente los medios anticonceptivos. 


\section{I}

\section{Introducción}

Estudios recientes (Rodríguez, 2004; Flórez y Núñez, 2003; CEPAL/CELADE, 2002) y datos de encuestas especializadas — como las de Demografía y Salud (www.measuredhs.com) — sugieren que en varios países de América Latina y el Caribe la fecundidad adolescente, es decir la que acontece antes de los 20 años de edad, ha aumentado en las últimas dos décadas, lo que la distingue de la fecundidad de las otras edades y de la fecundidad total, que han estado descendiendo sistemática y marcadamente (cuadro 1). Si a lo anterior se le suma que esta fecundidad genera adversidades, por lo menos para padres y prole (CEPAL/OIJ, 2004 y 2003; CEPAL/CELADE, 2002 y 2004; Flórez y Núñez, 2003; Menkes y Suárez, 2003; Molina, Sandoval y González, 2003; Silber y Castells, 2003; IPAS, 2001; Lete, de Pablo y otros, 2001; Gage, 1995), puede concluirse que se trata de un asunto que amerita exámenes e intervenciones específicos, sistemáticos y urgentes.

Ahora bien, intervenir sobre esta fecundidad requiere un conocimiento en detalle y actualizado de su naturaleza, de sus determinantes y, sobre todo, de quienes la experimentan. Este conocimiento apremia, por cuanto estudios recientes sobre el tema han destacado que una parte de la reproducción durante la adolescencia contemporánea ya no se ajusta al modelo que prevalecía hasta hace unas décadas (CEPAL/OIJ, 2004). Hasta el decenio de 1970 los países con tasas de fecundidad adolescente elevadas tendían a tener una fecundidad total alta. En la misma línea, las mujeres que iniciaban tempranamente su trayectoria reproductiva, es decir, que eran madres adolescentes, tendían a tener un número elevado de hijos hacia el final de dicha trayectoria. Esta vinculación forma parte de un síndrome que podríamos denominar de "comportamiento reproductivo tradicional", que persiste en países pobres y entre pueblos indígenas. Sus antecedentes suelen ser pautas de iniciación nupcial temprana y escaso uso de anticonceptivos.

Adicional a este patrón tradicional, el que ha emergido desde mediados del decenio de 1980 podría denominarse de modernidad ${ }^{1}$ reproductiva (o sexual) truncada, pues una trayectoria reproductiva final mo-

\footnotetext{
${ }^{1}$ El uso del vocablo "modernidad" no tiene connotaciones éticas ni implica una apreciación positiva. Se utiliza porque en las sociedades modernas (industrializadas, desarrolladas) está extendido e
}

derada (dos a tres hijos, como resultado del control deliberado de la fecundidad) es antecedida por una maternidad temprana. Se trata de muchachas que tienen su primer hijo durante la adolescencia y que luego están más motivadas a controlar la fecundidad o por su misma condición de madres pueden acceder con más facilidad a los programas de planificación familiar, lo que les permite materializar su deseo de una prole reducida.

El cuadro 2 ilustra a escala agregada esta creciente desvinculación entre iniciación e intensidad de la fecundidad, usando para ello la correlación simple entre las tasas específicas de fecundidad por edad y la tasa global de fecundidad de los países. Dado que esta última es la suma de las anteriores, cabe esperar una correlación alta. A escala mundial esto se verifica para todas las edades, salvo el grupo de 15 a 19 años, que se "desliga", siendo el caso de América Latina y el Caribe el de mayor desconexión. Esto se debe a que países con fecundidad total baja presentan una fecundidad adolescente moderada (Brasil, Colombia) y alta (República Dominicana), mientras países con una fecundidad total elevada (Haití y Bolivia) registran una fecundidad adolescente relativamente baja o moderada. Con todo, los países con fecundidad adolescente alta tienden a tener mayor fecundidad total (Guatemala, Nicaragua, Honduras).

Se ha subrayado, también, que la actual reproducción durante la adolescencia se distingue de la de antaño porque es más propensa a ocurrir al margen de una unión estable; por lo mismo, suele tener implicaciones intergeneracionales, pues la familia de las madres adolescentes aparece como pilar de apoyo ante la ausencia o debilidad de la relación de pareja (CEPAL/ OIJ, 2004).

Considerando los antecedentes regionales, las discusiones conceptuales y los imperativos prácticos antes descritos, este trabajo procura aportar conocimiento e información actualizados para mejorar la

institucionalizado el reconocimiento de la capacidad de las personas y las parejas de controlar su fecundidad y hay métodos disponibles para ejercer dicho control, de manera que la sexualidad puede efectivamente desligarse de la reproducción. En estas sociedades (en particular Europa occidental y Japón,) también se observa de manera sistemática que la baja de la fecundidad se acompaña de un retraso de su iniciación. 
CUADRO 1

América Latina (ocho países): Evolución tanto de las tasas específicas de fecundidad (por mil), según grupos quinquenales de edad, como de la tasa global de fecundidad, en años que se indican

\begin{tabular}{|c|c|c|c|c|c|c|c|c|}
\hline \multirow[t]{2}{*}{ País y año } & \multicolumn{7}{|c|}{ Grupos de edad } & \multirow{2}{*}{$\begin{array}{c}\text { Tasa global de } \\
\text { fecundidad }\end{array}$} \\
\hline & $15-19$ & $20-24$ & $25-29$ & $30-34$ & $35-39$ & $40-44$ & $45-49$ & \\
\hline Bolivia, 1989 & 98,5 & 234,5 & 245,1 & 198,7 & 141,5 & 67,4 & 21,6 & 5,0 \\
\hline Bolivia, 2003 & 84,0 & 183,0 & 179,0 & 145,0 & 114,0 & 51,0 & 12,0 & 3,8 \\
\hline Brasil, 1986 & 74,2 & 186,1 & 169,4 & 128,0 & 80,2 & 36,8 & - & 3,4 \\
\hline Brasil 1996 & 86,3 & 152,3 & 122,7 & 80,9 & 46,5 & 15,6 & 2,9 & 2,5 \\
\hline Colombia, 1986 & 73,4 & 176,8 & 159,9 & 118,0 & 77,1 & 28,0 & 7,5 & 3,2 \\
\hline Colombia, 2000 & 84,8 & 142,0 & 129,3 & 98,9 & 48,9 & 15,4 & 2,2 & 2,6 \\
\hline Guatemala, 1995 & 133,8 & 267,6 & 262,7 & 206,3 & 148,0 & 81,8 & - & 5,5 \\
\hline Guatemala, 2002 & 114,0 & 233,0 & 218,0 & 150,0 & 119,0 & 38,0 & 4,0 & 4,4 \\
\hline Haití, 1994/95 & 75,7 & 178,7 & 233,0 & 205,7 & 165,6 & 78,0 & 19,1 & 4,8 \\
\hline Haití, 2000 & 86,3 & 182,8 & 198,1 & 219,0 & 161,2 & 74,1 & 17,2 & 4,7 \\
\hline Perú 1986 & 78,9 & 183,9 & 198,7 & 161,3 & 122,2 & 63,7 & 14,4 & 4,1 \\
\hline Perú 2000 & 66,2 & 139,7 & 134,4 & 112,2 & 79,0 & 32,0 & 6,1 & 2,8 \\
\hline Nicaragua, 1997/98 & 130,1 & 192,3 & 161,8 & 122,2 & 78,4 & 32,2 & 9,5 & 3,6 \\
\hline Nicaragua 2001 & 119,0 & 178,0 & 145,0 & 108,0 & 64,0 & 26,0 & 6,0 & 3,2 \\
\hline República Dominicana 1986 & 99,7 & 202,4 & 195,3 & 127,0 & 70,9 & 32,4 & 8,4 & 3,7 \\
\hline República Dominicana 2002 & 116,0 & 190,0 & 145,0 & 97,0 & 41,0 & 8,0 & 1,0 & 3,0 \\
\hline
\end{tabular}

Fuente: www.measuredhs.com (procesamientos en línea con STATcompiler e informes nacionales en línea en los casos de Bolivia, 2003; Guatemala, 2002; Nicaragua, 2001, y República Dominicana, 2002).

CUADRO 2

Mundo y América Latina y el Caribe: Correlaciones simples entre las tasas específicas de fecundidad y la tasa global de fecundidad por países, 1995-2000

(Total mundial y dos muestras de América Latina y el Caribe)

\begin{tabular}{|c|c|c|c|}
\hline Tasa específica del grupo de edad & Total mundial ${ }^{\mathrm{a}}$ & América Latina y el Caribe ${ }^{b}$ & América Latina y el Caribe ${ }^{c}$ \\
\hline $15-19$ & 0,700 & 0,330 & 0,480 \\
\hline $20-24$ & 0,837 & 0,837 & 0,960 \\
\hline $25-29$ & 0,959 & 0,980 & 0,992 \\
\hline $30-34$ & 0,953 & 0,928 & 0,952 \\
\hline $35-39$ & 0,934 & 0,900 & 0,892 \\
\hline $40-44$ & 0,907 & 0,889 & 0,863 \\
\hline
\end{tabular}

Fuente: Cálculos basados en información obtenida en www.measuredhs.com.

a 51 países, incluyendo ocho de América Latina y el Caribe, con datos de encuestas levantadas con posterioridad a 1995.

b Bolivia, 1998; Brasil, 1996; Colombia, 2000; Guatemala, 1998/99; Haití, 2000; Nicaragua, 1997/98; Perú, $2000 ;$ República Dominicana, 2002.

c Sin Haití.

comprensión de la reproducción durante la adolescencia, sus tendencias y algunas de sus connotaciones para las muchachas y sus familias en Chile. Se eligió este país porque en él hay pocos estudios sociodemográficos recientes sobre esta materia, el tema está presente en la agenda pública, y la disponibilidad de microdatos de tres censos levantados en 20 años ofrece una oportunidad excepcional en materia de disponibilidad de información. Un primer objetivo es, entonces, verificar si Chile se incluye entre los países de la región donde la reproducción durante la adolescencia está aumentando, en contraposición con lo que ocurre en el resto de las edades. Adicionalmente, se apunta a evaluar las hipótesis sobre modalidades emergentes de reproducción durante la adolescencia, ya que por el avanzado estadio de Chile en la transición demográfica y porque sus índices socioeconómicos están muy por encima del promedio regional, resulta altamente improbable que esta reproducción se deba a patrones tradicionales. Ahora bien, 
aunque se hace referencia a las tasas específicas de fecundidad, el aporte novedoso de este estudio estriba en el examen de la maternidad adolescente. ${ }^{2}$ En efecto, la identificación de las madres menores de 20 años permite calcular indicadores de los patrones de reproducción durante la adolescencia y además hace posible caracterizarlas (a ellas y sus hogares) y con eso aportar insumos para diseñar políticas y arrojar luces sobre la naturaleza y los factores determinantes de este comportamiento.

\section{II}

\section{La fecundidad y la maternidad adolescentes en Chile: trayectoria en los últimos 40 años}

Chile no cuenta con encuestas de fecundidad. Hay tres encuestas sobre adolescentes y jóvenes (www.inj.cl), cuyos módulos sobre conducta sexual, nupcial y reproductiva son insuficientes y han sido poco explotados; también hay una encuesta de comportamiento sexual efectuada por la Comisión Nacional del SIDA (CONASIDA, 2000), y un par de encuestas sobre salud realizadas recientemente por el Instituto Nacional de Estadísticas (INE) y el Ministerio de Salud, pero aún escasamente difundidas y utilizadas. En cambio, Chile sí tiene estadísticas vitales de calidad aceptable y bases de microdatos censales en formato REDATAM ${ }^{3}$

\footnotetext{
${ }^{2}$ En demografía el concepto de fecundidad se refiere a la cantidad de hijos que tienen las mujeres durante su trayectoria reproductiva y puede ser calculada como el promedio de hijos de una cohorte real (paridez media, o final si la cohorte terminó su vida reproductiva) o como suma de las tasas específicas de fecundidad por edad (tasa global de fecundidad, cuya interpretación requiere algunos supuestos). La maternidad, en cambio, clasifica a las mujeres en una dicotomía: entre madres y no madres (nulíparas). Aunque normalmente los demógrafos se concentran en la fecundidad, por razones operativas y de política la maternidad adolescente ha adquirido creciente relevancia y visibilidad. En el plano operativo, por acontecer al inicio de la trayectoria reproductiva, el porcentaje de madres entre las menores de 20 años está estrechamente asociado con la fecundidad a esa edad; evidentemente, esa asociación tiende a diluirse con la edad, pues una maternidad relativamente universal puede darse en países de alta fecundidad total o de baja fecundidad total (esto último, si todas las mujeres son madres de un único hijo durante su vida). En el plano de políticas, a esa edad más que el promedio de hijos lo importante es la distinción entre haber o no haber tenido hijos. En este texto la expresión fecundidad adolescente se usará tanto para referirse de manera genérica a la reproducción biológica antes de los 20 años de edad como para referirse de manera particular a la intensidad de la reproducción en ese período, sea en términos de tasas específicas o de número medio de hijos. En cambio, la expresión maternidad adolescente aludirá de manera genérica a la adquisición de la condición de madre antes de los 20 años de edad y de manera específica a la proporción de madres entre las adolescentes.

3 REDATAM: Recuperación de datos para áreas pequeñas por microcomputador, del CELADE.
}

(para 1982, 1992 y 2002). Haciendo uso de estas dos últimas fuentes se acumula evidencia incontrarrestable sobre la resistencia al descenso de la fecundidad adolescente (gráficos 1 y 2), ya que la única tasa específica de fecundidad que no cayó abruptamente entre 1960 y 2001 fue la tasa del grupo de 15 a 19 años, que tendió a permanecer constante, con algunas oscilaciones; de hecho, su nivel en 2001 fue un 90\% del registrado en 1960, mientras que en el período 1960-2001 la fecundidad total y del resto de los grupos etarios se contrajo por lo menos en un $50 \%$.

Los datos censales tradicionalmente se han usado para estimaciones indirectas de la fecundidad mediante procedimientos desarrollados por demógrafos (Naciones Unidas, 1983) que hacen uso de las preguntas por el total de hijos nacidos vivos y de hijos tenidos el último año (captados en algunos censos con la consulta sobre fecha de nacimiento del último hijo). Tales estimaciones históricamente han sido efectuadas con los datos publicados y la experiencia sugiere que tienden a subestimar la fecundidad adolescente por la muy frecuente falta de respuesta a estas preguntas entre las muchachas menores de 20 años. Con todo, el desarrollo de procedimientos de corrección de este problema con datos agregados permite llegar a estimaciones relativamente confiables. Cálculos realizados mediante el método $\mathrm{P} / \mathrm{F}^{4}$ propuesto por Brass (Naciones Unidas, 1983) — cuya aplicación se hizo con un módulo especial de REDATAM que incluye algunos criterios de tratamiento y depuración de los datos-, sugieren

\footnotetext{
${ }^{4} \mathrm{El}$ procedimiento P/F de Brass es denominado así porque sus estimaciones se basan en un cociente entre la paridez acumulada $(\mathrm{P})$ que se obtiene con la pregunta por hijos nacidos vivos, y la fecundidad de momento (F) que se calcula con la pregunta por hijos nacidos vivos el último año. Los resultados del procedimiento son tasas específicas de fecundidad y tasa global de fecundidad ajustadas.
} 
GRÁFICO 1

Chile: Tasas específicas de fecundidad y tasa global de fecundidad (TGF), 1960-2000

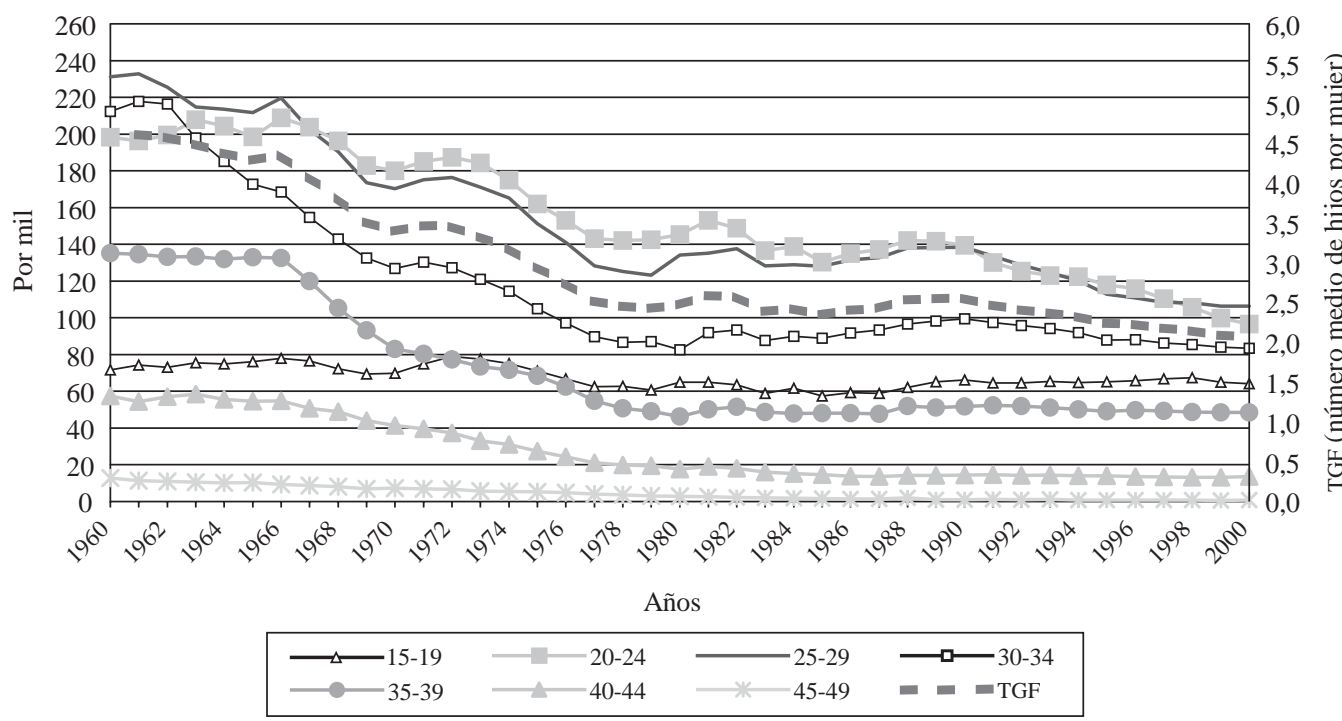

Fuente: Cálculos según estadísticas vitales proporcionadas por el Anuario de Demografía del Instituto Nacional de Estadísticas (INE, varios años). Para corregir el problema de oportunidad se usaron los datos de la publicación más actualizada.

GRÁFICO 2

Chile: Tasas específicas de fecundidad y tasa global de fecundidad (TGF), 1960-2000

$(1960=100)$

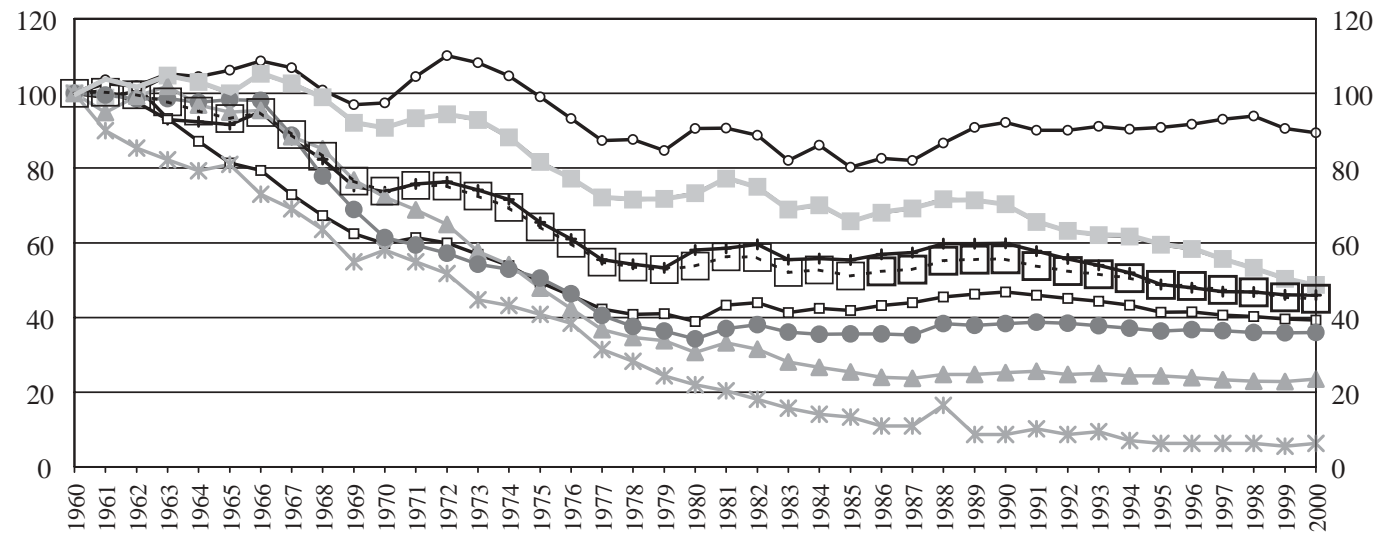

\begin{tabular}{|c|c|c|}
\hline 9 & $-20-24$ & $\longrightarrow 25-29$ \\
\hline
\end{tabular}

Fuente: Cálculos según estadísticas vitales proporcionadas por el Instituto Nacional de Estadísticas en su Anuario de demografía (INE, varios años). Para corregir el problema de oportunidad se usaron los datos de la publicación más actualizada.

que la tasa específica de fecundidad adolescente (1519 años de edad) se mantuvo casi constante, entre 65 y 70 por mil, en el período 1982-2002 (resultados disponibles mediante solicitud al autor).
También se han usado los datos censales publicados para estimar la cantidad absoluta y relativa de madres adolescentes. Así, en el cuadro 3, utilizando los datos publicados sobre la pregunta por hijos nacidos 
vivos en los censos de Chile de 1982, 1992 y 2002, se verifica que la maternidad adolescente ha tenido un ligero aumento en las dos últimas décadas. El cuadro también muestra la alta frecuencia de falta de respuesta a la pregunta por hijos nacidos vivos. Sin embargo, la experiencia de investigación en este tema sugiere que la gran mayoría de las muchachas que no responden son nulíparas (Rodríguez, 2004) y que ante la ausencia de información adicional o procedimientos de ajuste recomendables, puede considerárselas como tales: el error de medición que podría cometerse de este modo sería mucho menor que si se calculara la proporción de madres teniendo en cuenta solo las mujeres que respondieron la pregunta. De hecho, procediendo de esta última manera los niveles de maternidad adolescente en Chile se elevarían a $15,34 \%$ en $2002 .^{5}$

Ahora bien, el cuadro 3 refleja la forma como se indagaba la maternidad adolescente antes de tener acceso fácil a las bases de microdatos censales. En la actualidad este acceso es posible y muchas interrogantes sobre la fecundidad adolescente pueden comenzar a responderse. Asimismo, algunos de sus problemas de medición pueden encararse con nuevos procedimientos. Los cuadros 4 y 5 son el resultado de procesamientos especiales de las bases de microdatos censales, usando REDATAM, los que permiten avanzar en dos temas de importancia crucial: i) el contraste em-

CUADRO 3

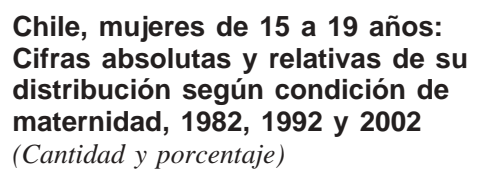

\begin{tabular}{lccc}
\hline Sin hijos & Con hijos & $\begin{array}{c}\text { No sabe o } \\
\text { no responde }\end{array}$ & Total \\
\hline $\begin{array}{l}1982 \\
429402\end{array}$ & 71541 & 151609 & 652552 \\
65,80 & 10,96 & 23,23 & 100,00 \\
1992 & & & \\
414158 & 69890 & 116515 & 600563 \\
68,96 & 11,64 & 19,40 & 100,00 \\
2002 & & & \\
426580 & 77291 & 124505 & 628376 \\
67,89 & 12,30 & 19,81 & 100,00 \\
\hline
\end{tabular}

Fuente: Publicaciones oficiales de los censos nacionales de población.

${ }^{5}$ Cuadro 3: $\left(\frac{77291}{628376-124505}\right) * 100$ pírico de la hipótesis sobre la creciente precocidad de la maternidad adolescente (INE, 2000), y ii) la evaluación de la tendencia según edad simple de la maternidad adolescente, imputándoles condición de maternidad a las muchachas sobre las cuales no se obtiene información en esa pregunta, y corrigiendo respuestas "inadmisibles". ${ }^{6}$ El cuadro 4 -que por estimar el porcentaje de maternidad sobre todas las mujeres estaría correcto si aquellas sin información fuesen nulíparas (hipótesis que pareciera cumplirse en la gran mayoría de las muchachas pero no en todas)—, ratifica los datos agregados de un aumento de la maternidad adolescente para todo el grupo de 15-19 años y que este aumento fue más marcado entre las muchachas de menos edad, sobre todo en el período 1992-2002, destacando un alza significativa de las madres a la edad de 15 años. ${ }^{7}$ Más llamativo aún, el cuadro 4 permite concluir que en todas las edades, salvo la mayor (19 años), aumentó la probabilidad de haber sido madre, lo que abona incuestionablemente las preocupantes hipótesis de una creciente precocidad de la maternidad adolescente. Estos resultados coinciden con los presentados por el INE (2000), aunque el indicador usado en esa publicación fue la tasa específica de fecundidad por edad simple y los datos provinieron de las estadísticas vitales para el período 1980-1998 (INE, 2000, p. 3).

El cuadro 5 ofrece cálculos que usan el procedimiento de imputación antes mencionado. Los resultados modifican levemente la imagen descrita en el cuadro 4, pues si bien ratifican un aumento de la maternidad adolescente entre 1982 y 2002, sobre todo en las edades menores, en el período 1992-2002 se detecta una estabilidad en la cual solo sobresale la edad de 15 años, que aumenta con fuerza su nivel de maternidad (aunque la información sobre dicha edad tiene problemas en 2002, como ya se indicó). Por cierto, estos resultados deben examinarse a la luz de los criterios

\footnotetext{
${ }^{6}$ Se imputó un valor 1 o 0 a las adolescentes que no respondieron a la pregunta al momento de ser censadas, usando un algoritmo simple según el cual: i) si su estado civil era soltera, fue clasificada con 0 hijos; ii) si su estado civil era casada, conviviente, separada o anulada fue clasificada con 1 hijo. Además, por los errores que presenta el censo, se procedió a dar valores máximos de hijos que una adolescente puede biológicamente tener. Para ello se recodificó de la siguiente manera: i) adolescentes entre 15 y 17 años: pueden declarar un número máximo de tres hijos; ii) adolescentes entre 18 y 19 años: pueden declarar un número máximo de cuatro hijos. 7 6,3\% en 2002, es decir, tres veces el porcentaje de 1992. Estas cifras serán revisadas más adelante, considerando antecedentes adicionales, porque parecen estar afectadas por errores sistemáticos de medición que tal vez podrían explicar la gran magnitud del alza (aunque no la tendencia al alza).
} 

según edad simple, 1982, 1992 y $2002^{a}$

\begin{tabular}{|c|c|c|c|c|c|c|c|c|c|c|c|c|}
\hline \multirow[t]{2}{*}{ Edad } & \multicolumn{4}{|c|}{1982} & \multicolumn{4}{|c|}{1992} & \multicolumn{4}{|c|}{2002} \\
\hline & Total & Madres & NS/NR & $\%$ de madres & Total & Madres & NS/NR & $\%$ de madres & Total & Madres & NS/NR & $\%$ de madres \\
\hline 15 & 132898 & 2077 & 40744 & 1,56 & 112098 & 2317 & 25553 & 2,07 & 140646 & 8902 & 34764 & 6,33 \\
\hline 16 & 128085 & 5315 & 30866 & 4,15 & 116439 & 5609 & 24499 & 4,82 & 123619 & 6327 & 26870 & 5,12 \\
\hline 17 & 131254 & 11686 & 27952 & 8,90 & 122678 & 12078 & 23828 & 9,85 & 120195 & 12204 & 23946 & 10,15 \\
\hline 18 & 131725 & 20555 & 24308 & 15,60 & 127211 & 20443 & 23356 & 16,07 & 120763 & 20198 & 20368 & 16,73 \\
\hline 19 & 128590 & 31908 & 20303 & 24,81 & 122137 & 30288 & 18434 & 24,80 & 123153 & 29660 & 18557 & 24,08 \\
\hline Total & 652552 & 71541 & 144173 & 10,96 & 600563 & 70735 & 115670 & 11,78 & 628376 & 77291 & 124505 & 12,30 \\
\hline
\end{tabular}

Fuente: Procesamiento especial de las bases de microdatos censales.

a Los procesamientos de los microdatos proporcionan una información que no coincide exactamente con los datos publicados por el INE en 1992 y 1982 (cuadro 3). Indagando las razones para esta discrepancia se descubrió que en 1992 el INE asignó a la categoría no sabe/no responde todas las respuestas "anómalas por ser demasiado altas": 15 años con más de tres hijos; 16 años con más de cuatro hijos; 17 años con más de cinco hijos; 18 años con más de seis hijos; 19 años con más de siete hijos. En el cuadro 4 estos casos (pocos en 1992) forman parte de las madres porque su perfil de estado civil y actividad educativa es mucho más parecido al de las muchachas con hijos; es decir, declararon mal su número de hijos pero casi con seguridad habían tenido hijos. Respecto de la diferencia con 1982 , esta se debe a que la publicación del INE usó la pregunta filtro sobre haber o no haber tenido hijos para identificar la "fecundidad no declarada", y no la pregunta directa sobre número de hijos nacidos vivos tenidos que fue la usada para obtener los datos del cuadro 4 . Y un número menor de casos (justamente la discrepancia entre el tabulado oficial y el procesamiento de los microdatos) sin respuesta en la pregunta filtro fue clasificado en la categoría de nulíparas en la pregunta sobre número de hijos nacidos vivos tenidos, sin que se explique por qué se hizo. En todo caso, su efecto es irrelevante, pues atañe a las muchachas con "fecundidad desconocida" y no a las madres, respecto a las cuales las cifras coinciden entre la publicación y el procesamiento.

Chile, mujeres de 15 a 19 años: Cifras absolutas y relativas (con imputación de condición de maternidad a las muchachas que no responden o con respuesta anómala) de la condición de maternidad según edad simple, 1982, 1992 y 2002

\begin{tabular}{|c|c|c|c|c|c|c|c|c|c|}
\hline \multirow[t]{2}{*}{ Edad } & \multicolumn{3}{|c|}{1982} & \multicolumn{3}{|c|}{1992} & \multicolumn{3}{|c|}{2002} \\
\hline & Total & Madres & $\%$ de madres & Total & Madres & $\%$ de madres & Total & Madres & $\%$ de madres \\
\hline 15 & 132898 & 3058 & 2,30 & 112098 & 5012 & 4,47 & 140646 & 11331 & 8,05 \\
\hline 16 & 128085 & 5761 & 4,50 & 116439 & 7959 & 6,84 & 123619 & 7392 & 5,97 \\
\hline 17 & 131254 & 12465 & 9,50 & 122678 & 14320 & 11,67 & 120195 & 13316 & 11,07 \\
\hline 18 & 131725 & 21554 & 16,36 & 127211 & 23332 & 18,34 & 120763 & 21472 & 17,78 \\
\hline 19 & 128590 & 33322 & 25,91 & 122137 & 32636 & 26,73 & 123153 & 31271 & 25,39 \\
\hline Total & 652552 & 76160 & 11,67 & 600563 & 83259 & 13,86 & 628376 & 84782 & 13,49 \\
\hline
\end{tabular}

Fuente: Procesamiento especial de las bases de microdatos censales.

que se utilizaron para obtenerlos, pero ratifican el hallazgo central de que en los últimos 20 años la maternidad adolescente aumentó en Chile y que ese incremento ha sido más marcado entre las muchachas menores. Tanto o más importante que la frecuencia relativa de madres entre las adolescentes del orden de un $13 \%$ en el censo (cuadros 4 y 5 ) - dato que puede conducir a lecturas apresuradas que resten impor- tancia a la reproducción temprana como asunto de política pública porque atañe a una minoría de las muchachas - es el valor obtenido para la edad de 19 años, que es el que más se aproxima a la probabilidad de ser madre en la adolescencia. Y según ese dato al menos una de cada cuatro mujeres chilenas ha sido madre durante su adolescencia en las últimas dos décadas. 


\section{III}

\section{¿En qué contexto nupcial tienen sus hijos las madres adolescentes?}

Históricamente, la maternidad temprana ha estado asociada con una mayor probabilidad de ocurrir en un contexto informal (convivencia) o de soltería (Guzmán, Hakkert y otros, 2001; Buvinic, 1998). Recientemente el INE reconstruyó series de fecundidad y maternidad según estado civil de la madre que llegan a cifras de soltería de 90\% entre las madres de 15 años (INE, 2000, p. 4). Sin embargo, por basarse en registros administrativos (estadísticas vitales) estas cifras abultan la proporción de madres solteras porque no reconocen el estatus de conviviente, que sí capta el censo. En 1982 la mayor parte de las madres adolescentes estaba casada, ${ }^{8}$ pero las madres solteras constituían un $40 \%$ del total; la convivencia, por su parte, era poco usual. En 1992 las madres adolescentes solteras ya eran mayoría, aunque por un margen ligero. En 2002 el cambio se había consolidado totalmente, pues el 55\% de las madres declaró ser soltera ${ }^{9}$ y las que convivían superaron a las casadas; de hecho, solo un $17 \%$ de las madres de 15 a 19 años de edad estaba casado (gráfico 3).

El gráfico 4 muestra cómo evolucionó la proporción de solteras según condición de maternidad entre 1982 y 2002. En todas las edades (salvo el caso anómalo de la edad de 15 años en 2002) se verifica un aumento de la proporción de solteras entre las madres adolescentes, lo que descarta que la evolución de las

GRÁFICO 3

Chile, mujeres de 15 a 19 años de edad: Distribución relativa según

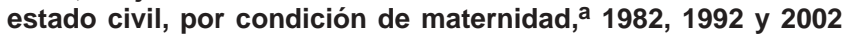

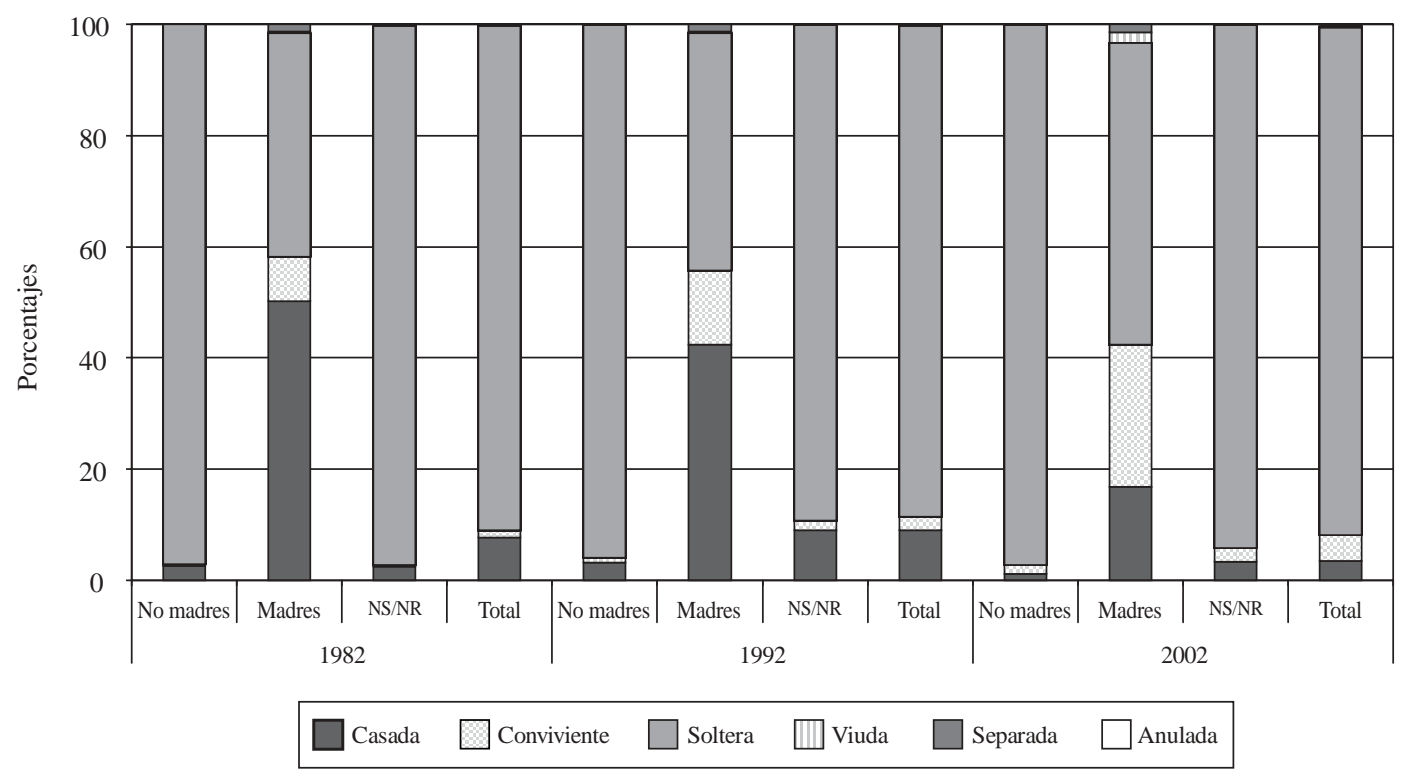

Fuente: procesamiento especial de las bases de microdatos censales.

a $\mathrm{NS} / \mathrm{NR}=$ no sabe/ no responde.

${ }^{8}$ Aunque no forzosamente con el padre de la criatura.

\footnotetext{
${ }^{9}$ Declaración que significa que no se habían casado y que no estaban conviviendo a la fecha del censo. Por cierto, pudieron haber "convivido" con una pareja en algún momento de su vida, pero el censo no recoge ese antecedente.
} 
GRÁFICO 4 Chile, mujeres de 15 a 19 años de edad: Proporción de solteras según condición de maternidad ${ }^{\mathrm{a}}$ y edad simple, 1992 y 2002

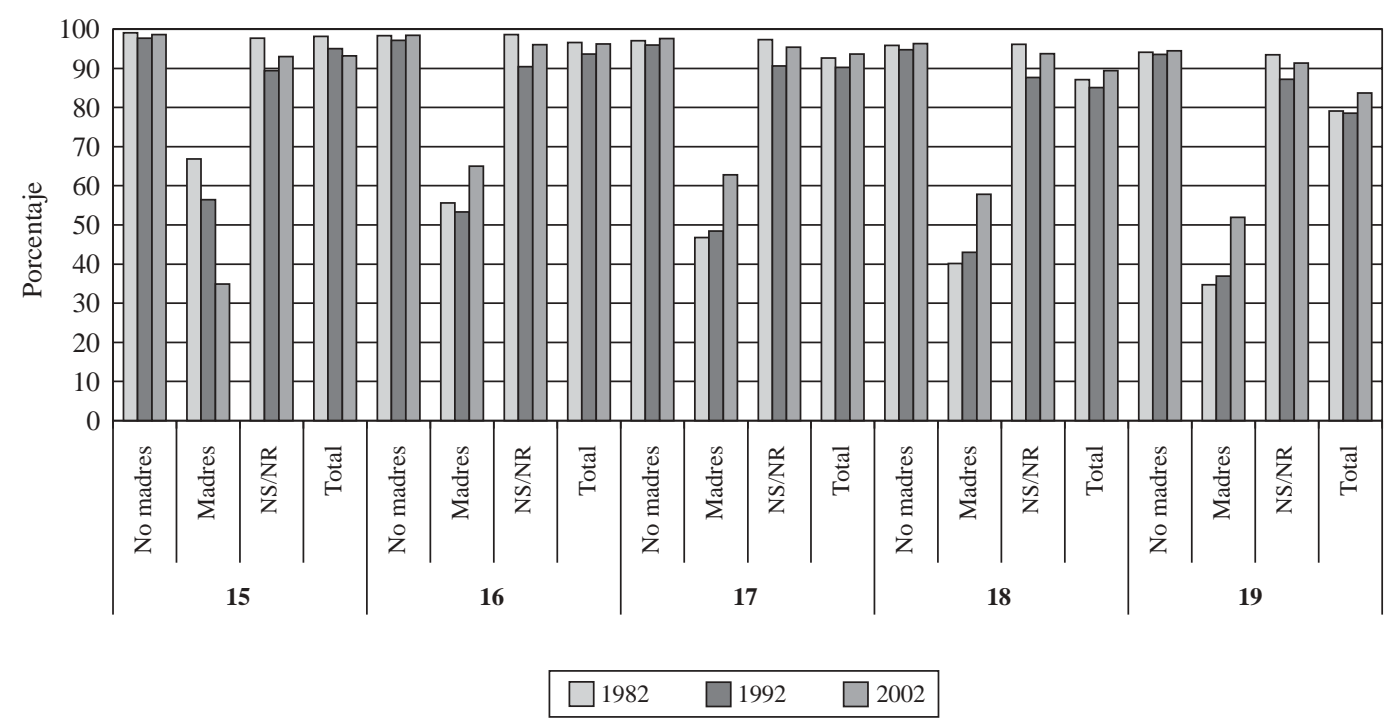

Fuente: Procesamiento especial de las bases de microdatos censales.

a $\mathrm{NS} / \mathrm{NR}=$ no sabe/no responde

cifras agregadas del gráfico 3 respondan a algún efecto de la composición etaria. Además, se verifica que mien- tras más precoz es la maternidad más probabilidad hay de que se dé en contextos de soltería ${ }^{10}$ (gráficos 3 y 4).

\section{IV}

\section{Dónde viven y qué hacen las madres adolescentes: ¿emancipación o enclaustramiento?}

La maternidad entraña un cambio de estatus para las adolescentes. Cuando predomina un patrón tradicional, este cambio se asocia con la nupcialidad o es resultado de ella y por ese motivo lleva a la constitución de un nuevo hogar, a veces en una vivienda independiente de la de los padres y, otras, en la misma de alguno de ellos. La modalidad de maternidad adolescente que emerge, descrita en la sección anterior, genera un escenario nuevo para las muchachas que tienen hijos. Esto porque la falta de una pareja hace difícil pensar que el embarazo las conduzca a la formación de familia y/o a la independencia del hogar de origen. Por lo mismo ellas deben buscar fuentes de apoyo en otras instancias que, siguiendo la clásica distinción de
Esping-Andersen (1999), pueden ser: i) la familia que cobija, cuida, destina tiempo a la crianza y proporciona recursos; ii) el Estado que impide la discriminación, provee escuelas, guarderías y servicios de consejería, proporciona subsidios y define garantías, y iii) el mercado que ofrece empleo.

El gráfico 5 presenta evidencia bastante contundente sobre el apoyo que reciben las madres adolescentes:

\footnotetext{
${ }^{10}$ Cabe advertir que la condición de soltería no es sinónimo de ausencia de padre, pues para algunas parejas de adolescentes la maternidad/paternidad se vive al margen del casamiento o la convivencia, sin que esto signifique ausencia de lazo sentimental y/o de interacción regular (Buvinic, 1998, p. 5).
} 
como cabía esperar, madres y no madres se diferencian, pues estas últimas viven con sus padres u otros parientes casi sin excepción, mientras que entre las primeras hay una proporción que ha formado un hogar (aunque no forzosamente una vivienda) independiente. Con todo, la conclusión que emerge de estos datos es que la familia de las madres adolescentes es el principal soporte de la crianza. En efecto, la mayoría de ellas vive con su familia o la de su pareja, como lo demuestra el hecho de que la relación predominante con el jefe de hogar sea la de hija/nuera, siendo la situación más frecuente la residencia con la familia de la muchacha. La formación de un hogar independiente parece difícil, ya que en 2002 eran más las madres adolescentes que vivían en el hogar de algún pariente secundario o de un no pariente (sumados) que aquellas que vivían en un hogar encabezado por su cónyuge (gráfico 5). Como podía anticiparse, mientras más precoz es la maternidad más importante es el papel de la familia de origen; incluso así, las madres de 19 años viven en su mayoría con sus padres o suegros (gráfico 6).

Los datos de tendencia (2002-1992) revelan que el papel de la familia como instancia de acogida de las madres adolescentes es cada vez mayor, lo que se vincula con el ya mostrado incremento de la maternidad adolescente en condiciones de soltería (gráficos 5 y 6 ). Es decir, la familia de origen pareciera llenar, al menos en parte, el espacio que deja la ausencia de pareja para las muchachas. Esta constatación estadística no permite especificar el apoyo efectivo que la familia brinda a la madre adolescente y su prole; los datos censales sólo acreditan que proporciona techo y alimento, pero no captan información sobre otras modalidades de apoyo como: tiempo destinado a atender los niños/as, transferencias de recursos, cariños, afectos y cuidados. Se necesitan investigaciones focalizadas, algunas de ellas más bien cualitativas, para precisar el papel de la familia en el desenvolvimiento del binomio madre adolescente-hijo/a.

El importante apoyo que presta la familia, sin embargo, no parece ser suficiente para que las muchachas compatibilicen la crianza con la escuela o el trabajo. El gráfico 7 es elocuente, pues según el censo de 2002 la probabilidad de dedicarse solo a estudiar pasa de $80 \%$ para las mujeres de 15 a 19 años que no han tenido hijos a apenas un $20 \%$ para las que sí han tenido. Pero la salida del sistema escolar de las madres adolescentes no las hace más proclives a participar en el mercado de trabajo; en efecto, su actividad diaria corresponde mayoritariamente a los quehaceres del hogar, lo que refuerza la hipótesis de que la maternidad precoz obstruye simultáneamente las trayectorias escolares y las laborales. Así, esta evidencia apunta a que la reproducción temprana se asocia con deserción escolar —en una relación compleja, como se explicará más adelante- pero no con el ingreso de las muchachas al mercado de trabajo (CEPAL/OIJ, 2004 y 2003; Rodríguez, 2004; SERNAM, 2004).

Chile, mujeres de 15 a 19 años: Distribución relativa de la posición en el hogar según condición de maternidad,a 1992 y 2002

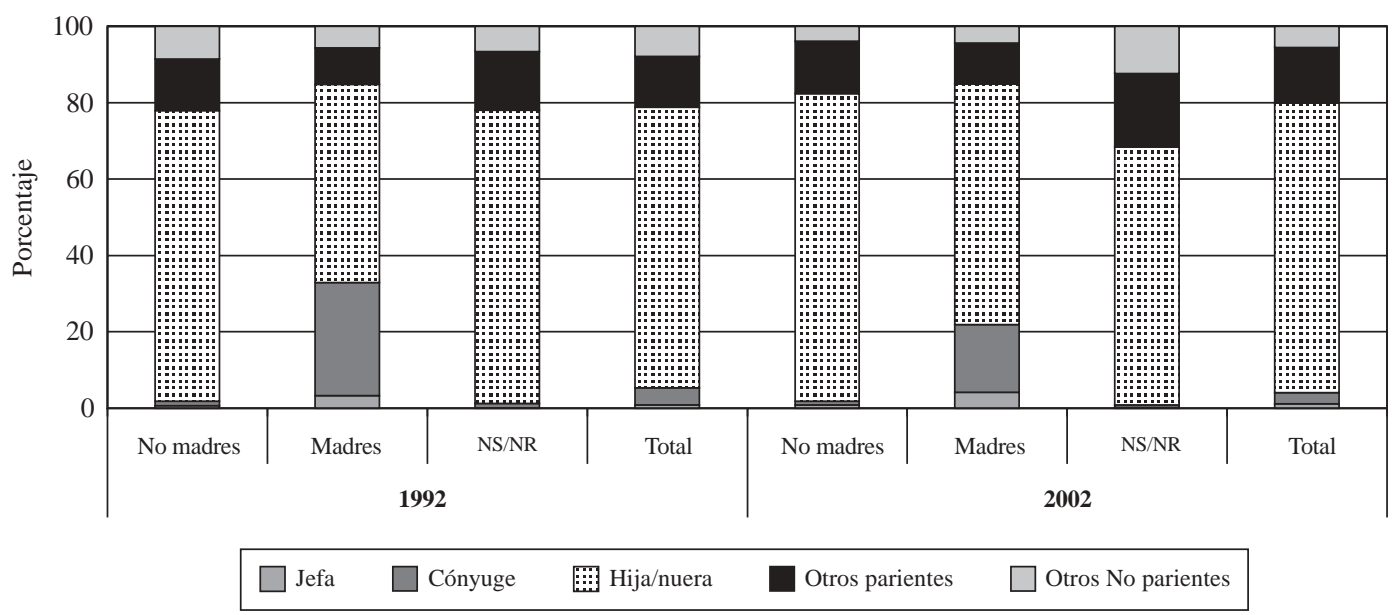

Fuente: Procesamiento especial de las bases de microdatos censales.

a $\quad$ NS/NR $=$ no sabe/no responde. 
GRÁFICO 6

Chile, mujeres de 15 a 19 años: Distribución relativa de posición en el hogar, según edad simple y condición de maternidad, ${ }^{\mathrm{a}} 1992$ y 2002

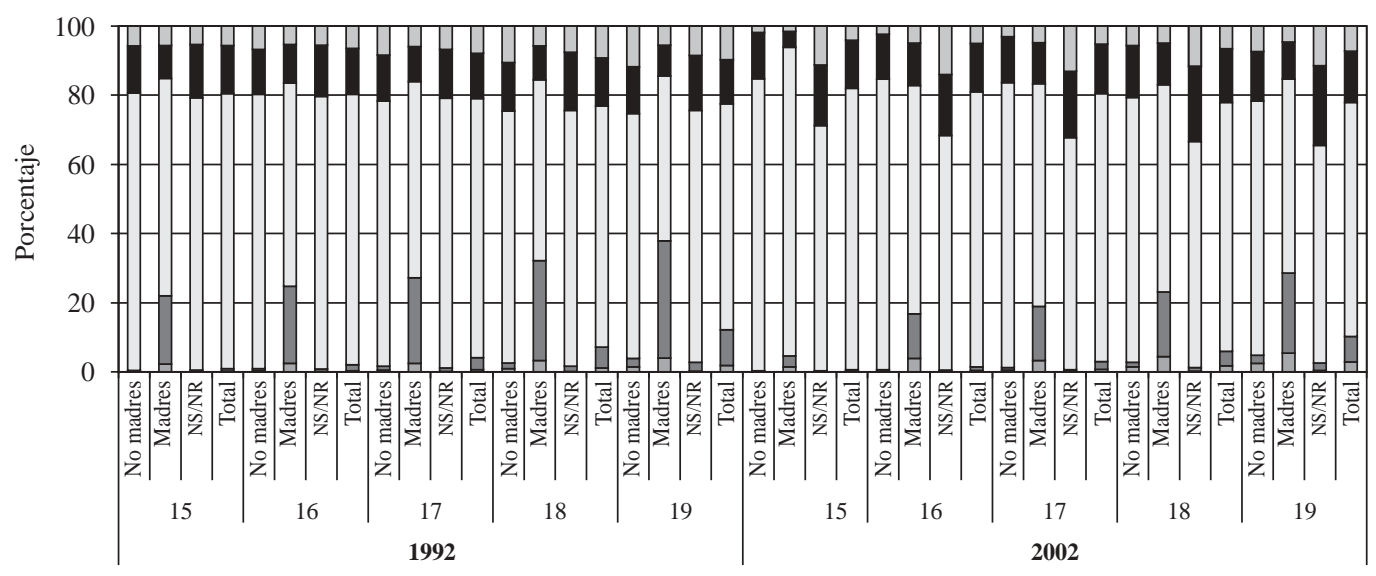

$\square$ Jefa $\square$ Cónyuge $\square$ Hija/nuera $\square$ Otros parientes $\square$ Otros No parientes

Fuente: Procesamiento especial de las bases de microdatos censales.

a $\mathrm{NS} / \mathrm{NR}=$ no sabe/no responde.

GRÁFICO 7

Chile, mujeres de 15 a 19 años: Distribución relativa de la actividad económica según condición de maternidad, ${ }^{\mathrm{a}} 1992$ y 2002

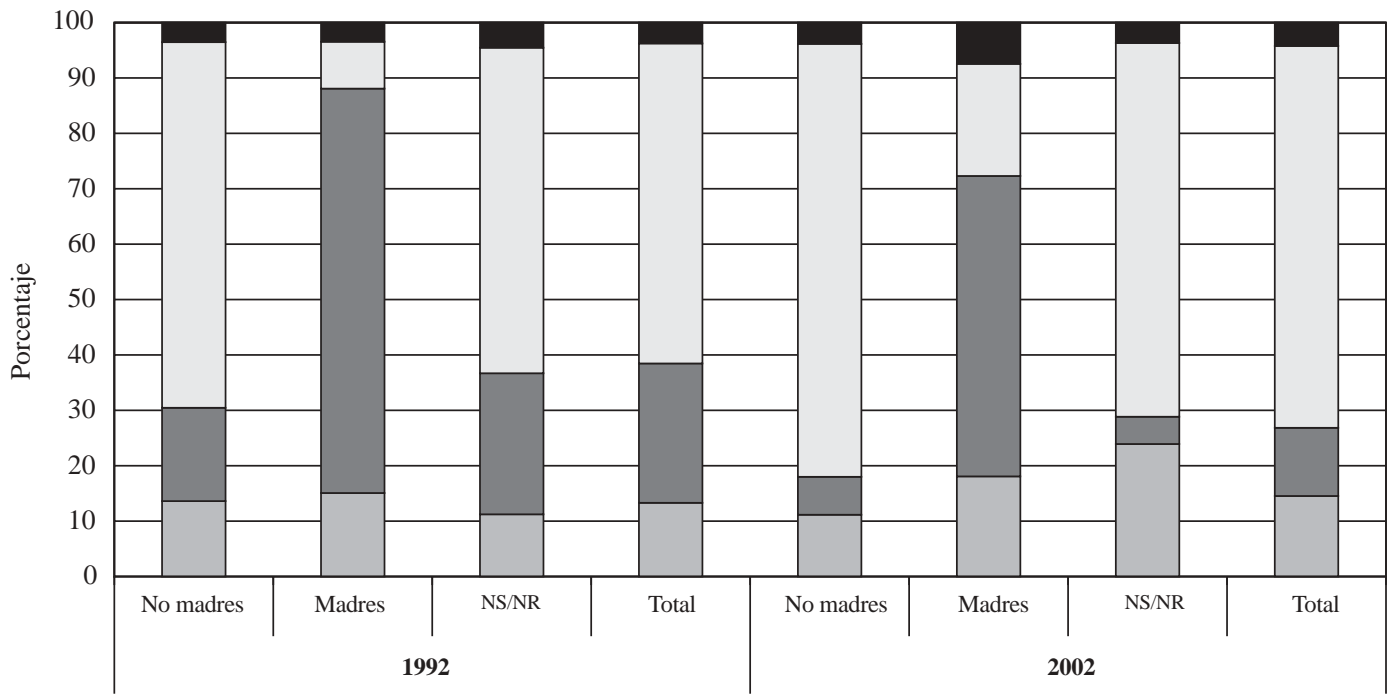

Condición de maternidad y años

$\square$ Económicamente activa $\square$ En casa $\square$ Estudia $\square$ Otra situación

Fuente: Procesamiento especial de las bases de microdatos censales.

a $\mathrm{NS} / \mathrm{NR}=$ no sabe/no responde. 
El examen por edades simples permite refinar el análisis porque la trayectoria escolar universal sólo llega hasta la educación media, es decir, hasta los 17 a 18 años de edad. Por lo tanto, en el grupo de 15 a 19 años se mezclan situaciones diferentes en materia de trayectoria escolar. El gráfico 8 presenta esta información y arroja hallazgos importantes. Se ratifica el patrón que distingue entre madres y no madres adolescentes: las primeras tienen una probabilidad mucho mayor de estar fuera del sistema escolar y dedicadas a actividades domésticas. ${ }^{11}$ Según el censo de 2002, el $85 \%$ de las muchachas de 17 años de edad que no han tenido hijos es estudiante, mientras que entre las madres de esa edad sólo lo es el 30\%. Cabe subrayar que la brecha entre ambos grupos se debe a que las madres de 17 años tienen 10 veces más probabilidad de dedicarse a "quehaceres del hogar" que las no madres y sólo dos veces más probabilidad de ser activas. Definitivamente, la maternidad adolescente conduce a enfrentar la crianza mediante la dedicación doméstica y no a través de la inserción laboral, pese a que el apoyo familiar permitiría, en principio, una redistribución de responsabilidades que liberaría tiempo para que las madres adolescentes trabajasen. Incluso más, cuando se comparan madres y no madres de 19 años —edad a la cual la mayor parte de las muchachas no estudialas primeras tienen una menor probabilidad de ser activas (gráfico 8).

GRÁFICO 8

Chile, mujeres de 15 a 19 años: Distribución relativa de condición económica según edad simple y condición de maternidad, ${ }^{a} 1992$ y 2002

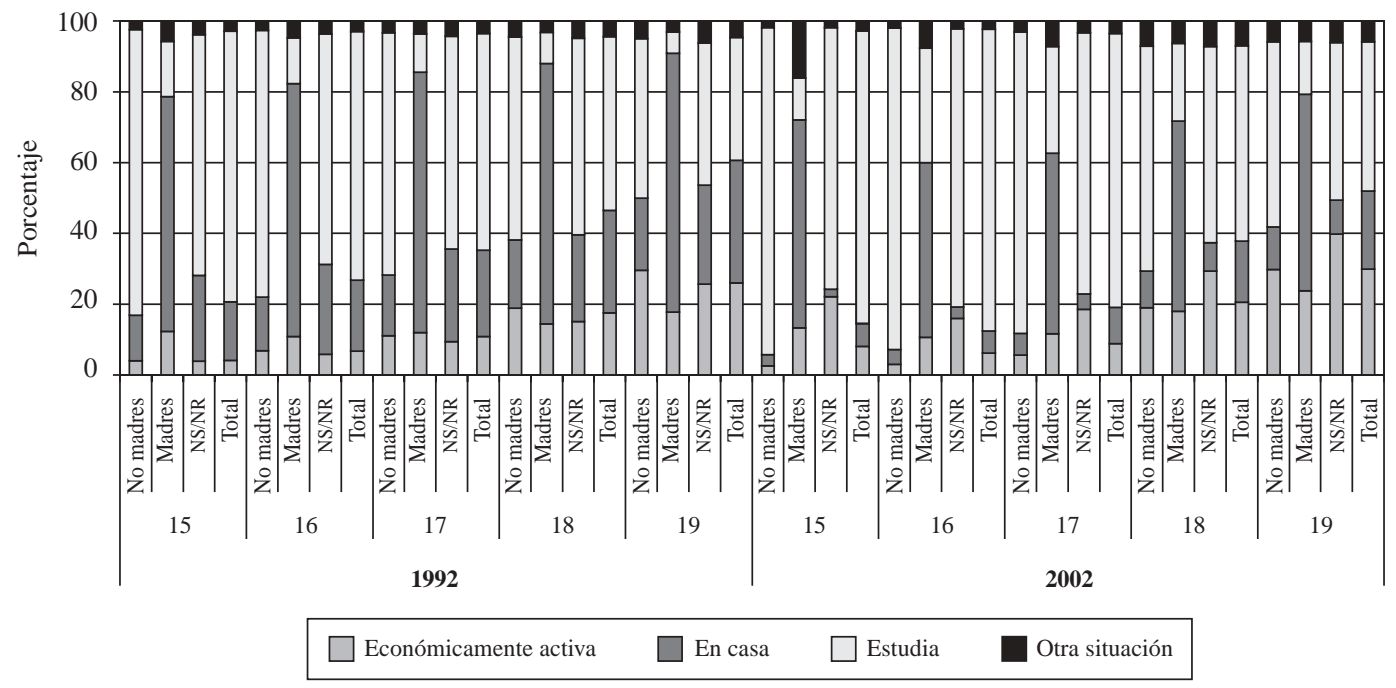

Fuente: procesamiento especial de las bases de microdatos censales.

a $\mathrm{NS} / \mathrm{NR}=$ no sabe/no responde.

11 Sobre la condición de estudiante, las comparaciones directas entre
los tres censos pueden tener problemas. No es posible usar la pre-
gunta directa por asistencia a la escuela porque en los censos de
1992 y 2002 no se incluyó esa pregunta. Entonces, se utiliza la
consulta relativa a condición de actividad, que sí está en los tres
censos y considera la categoría de respuesta "estudiante". Ahora
bien, según los manuales de los encuestadores, la información que
se recoge es comparable, pues en los tres censos capta la actividad
predominante de las personas durante la semana previa al censo.
Sin embargo, la redacción y las alternativas de respuesta en el cuestionario difieren en el censo de 1992 respecto de los censos de 1982 y 2002 . Específicamente, en el censo de 1992 la consulta no explicita que se trata de la "actividad predominante" y, además, la categoría de respuesta alude a "estudiando sin trabajar". Las consecuencias prácticas de estas diferencias son relativamente predecibles (una cantidad de estudiantes que clasifica como ocupados por haber trabajado alguna fracción de la semana, lo que elevaría los indicadores de deserción) pero imposibles de estimar con precisión. 


\section{Maternidad adolescente, trayectoria escolar y deserción: luces y sombras}

Las cifras presentadas ya sugieren que la maternidad temprana es poco compatible con la asistencia a la escuela. Las del gráfico 9 ratifican los hallazgos previos, pues de manera sistemática las adolescentes que han tenido hijos encaran una probabilidad mucho mayor de estar fuera del sistema escolar: en 2002 solo una de cada cinco adolescentes madres era estudiante, mientras que entre las que no habían tenido hijos lo eran cuatro de cada cinco. Esto último cobra particular relevancia en el caso de las muchachas de 16 y 17 años, ya que a esa edad debieran estar cursando los dos últimos grados de la educación media y, por ende, su condición de no estudiante sugiere que no han alcanzado los niveles de educación obligatorios estipulados por la ley vigente y considerados como mínimos por la sociedad y los mercados actuales. En este grupo etario $^{12}$ la maternidad se asocia con una probabilidad cinco veces mayor de estar fuera del sistema escolar y, de hecho, sólo un $21 \%$ de las madres de esa edad es estudiante (gráfico 9).

Pese a lo anterior, los resultados que muestra el gráfico 9 proporcionan importantes antecedentes sobre la evolución de la condición de estudiante de las adolescentes, destacando un aumento sostenido tanto para las madres como para las nulíparas. La probabilidad de no ser estudiante entre las nulíparas de 15 a 19 años cayó de $40 \%$ en 1982 a cerca de $20 \%$ en 2002 . En cambio, en 1982 la incompatibilidad entre ser madre y estudiar

GRÁFICO 9

Chile: Mujeres de 15 a 19 años que no estudian, por edades simples según condición de maternidad, 1982, 1992 y 2002

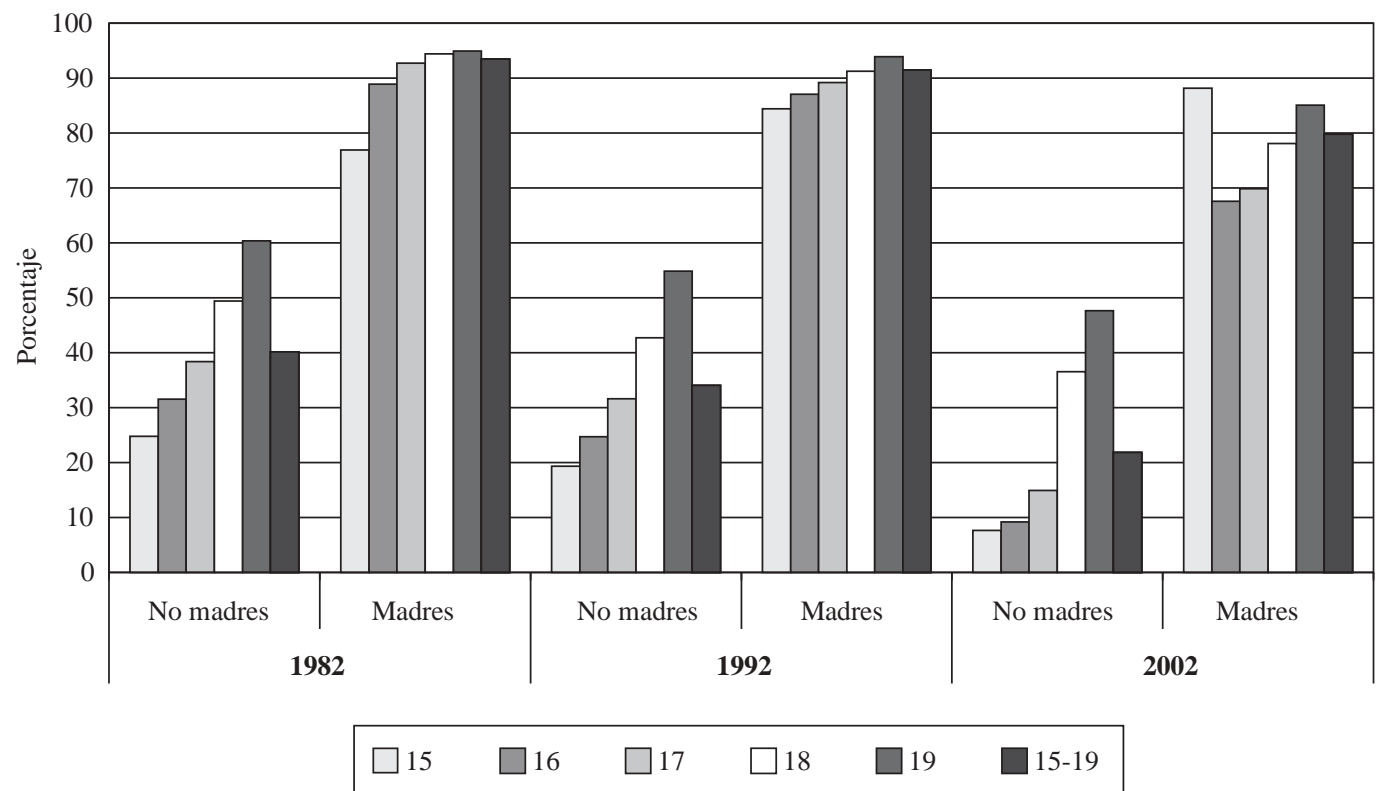

Fuente: Procesamiento especial de las bases de microdatos censales.

\footnotetext{
${ }^{12}$ Edades 16 y 17, pues el comportamiento de las madres de 15 años es anómalo y a los 18 años un grupo de las muchachas ya ha concluido oportunamente su educación media y ha dejado de estu-
}

diar sin ser desertora. Esto último se hace evidente en el 2002, en el salto entre las edades 17 y 18 de la proporción de no madres que no estudia (gráfico 9). 
era casi total, con porcentajes de madres adolescentes que estudiaban inferiores al 10\%. En 2002 esos índices superaban ligeramente el $20 \%$ y en las edades claves para completar los 12 años de educación obligatoria, esa probabilidad superaba el 30\% (gráfico 9).

Aunque poderosa, toda la evidencia anterior no es suficiente para concluir que la maternidad temprana sea la causa de que se trunque la trayectoria escolar de las muchachas. Sobre esta relación existe un gran debate, porque hay encuestas especializadas en la región que sugieren que en la mayor parte de los casos la deserción es previa al embarazo. Esta discusión tiene plena vigencia en Chile, aunque la evidencia disponible para contrastar empíricamente las posiciones es débil (Molina, Ferrada y otros, 2004). De hecho, algunos estudios recientes han llegado a conclusiones polémicas a partir de muestras que no son representativas de los y las adolescentes (Paz Ciudadana, Adimark y otros, 2002); otros estudios basados en muestras pequeñas proporcionan estimaciones que varían mucho (Molina, Ferrada y otros, 2004). Una cifra robusta es la proporcionada por la encuesta de caracterización socioeconómica nacional (CASEN) levantada el año 2000, según la cual no más de un $20 \%$ de las deserciones femeninas se debió a embarazo o maternidad (www.mideplan.cl/ sitio/Sitio/estudios/documentos/desercion19.pdf). Este dato es corroborado por la Tercera Encuesta de Juventud, donde solo un $10 \%$ de los jóvenes que no estudia declara que la causa es la maternidad/embarazo. ${ }^{13}$

El censo no indaga sobre la fecha de la deserción ni sobre la situación de embarazo o maternidad cuando ocurrió la deserción. Sin embargo, usando como instrumento analítico y operativo la noción de trayectoria educativa, es posible profundizar sobre este asunto. Habida cuenta del carácter tentativo de este examen, así como de su aporte en términos de política, sólo se presentarán los resultados obtenidos con el censo de 2002. La noción de trayectoria educativa ha sido usada en trabajos previos (Rodríguez, 2004) para tener una primera aproximación a la relación entre deserción y embarazo. Esta noción se define según un algoritmo simple que relaciona la edad de la persona y el curso alcanzado, en el entendido de que hay una trayectoria "normal" según la cual se espera que a una determinada edad la persona haya llegado a un cierto grado escolar. Para facilitar los cálculos se trabaja con la edad

\footnotetext{
13 Estos datos no refieren en rigor a deserción, porque incluyen a los jóvenes que no estudian porque terminaron su educación media (www.injuv.gob.cl/cedoc_archivos/estudios/Tercera_encuesta.pdf).
}

de 17 años y solo con las muchachas con condición de maternidad conocida. Se definen tres categorías de trayectoria educativa: rezagada (menos de ocho años de escolaridad), atrasada (ocho o nueve años de escolaridad) y normal (diez o más años de escolaridad). ${ }^{14}$

Un primer resultado se expone en el cuadro 6, que aprovechando una de las fortalezas del censo incluye también cifras absolutas. Como podía esperarse, el perfil educativo difiere significativamente entre madres y no madres, al punto que entre las primeras predomina la categoría de trayectoria educativa rezagada, que es marginal entre las no madres. Este último hallazgo abona, aunque de manera indirecta, la discusión sobre el orden temporal de la relación embarazo-deserción. En efecto, si a los 17 años una muchacha no ha logrado completar la enseñanza básica hay una alta probabilidad de que sea una desertora, ${ }^{15}$ además, por su edad al momento del censo y el grado alcanzado, puede estimarse que, en promedio, salió del sistema escolar entre tres y cuatro años antes del censo, es decir cuando tenía entre 13 y 14 años de edad. Por otra parte, las madres de 17 años, en su gran mayoría, tienen hijos menores de dos años de edad, es decir, fueron madres después de cumplir los 15 años. De lo anterior se deduce que es altamente probable que se trate de deserción previa al embarazo. Si la trayectoria es atrasada, es difícil llegar a una conclusión tentativa del orden de los acontecimientos. En cambio, si la trayectoria es normal, hay una alta posibilidad de que la deserción (que involucra sólo al $40 \%$ de las madres adolescentes de esa edad y trayectoria educativa), se haya debido al embarazo. En suma, dos conclusiones tentativas emergen: i) parece más frecuente el caso de deserción y luego embarazo que la situación que sigue el orden inverso; ii) una trayectoria educativa "normal" eleva notablemente la probabilidad de permanecer en la escuela después del embarazo. Esto se ratifica en el gráfico 10, que indica que una trayectoria rezagada anticipa deserción casi con independencia de la condición de maternidad y que, como contrapartida, entre las madres de

\footnotetext{
${ }^{14}$ Los años de escolaridad es una variable construida con base en dos consultas que se repiten sistemáticamente en los tres censos usados en este trabajo: último grado y nivel educativo aprobados. Así, un valor de 12 corresponde a una persona que logró enterar el cuarto medio y que puede haber concluido ahí su formación o que puede estar cursando el primer año del nivel terciario (universitario o técnico) o el denominado "quinto medio" de los establecimientos de educación secundaria técnico-profesional.

${ }^{15}$ De hecho, los mismo datos censales confirman esta hipótesis: en 2002 solo 392 de las 5.049 madres de 17 años con trayectoria educativa rezagada era estudiante.
} 
CUADRO 6

Chile: Mujeres de 17 años de edad, con condición de maternidad conocida, ${ }^{a}$ por trayectoria educativa según condición de maternidad, 2002

(Cifras absolutas y relativas)

\begin{tabular}{|c|c|c|c|c|c|c|}
\hline \multirow{2}{*}{ Trayectoria educativa } & \multicolumn{3}{|c|}{ Cantidad } & \multicolumn{3}{|c|}{ Estructura relativa $(\%)$} \\
\hline & No madres & Madres & Total & No madres & Madres & Total \\
\hline Rezagada & 7919 & 5049 & 12968 & 9,4 & 41,4 & 13,5 \\
\hline Atrasada & 18966 & 4029 & 22995 & 22,6 & 33,0 & 23,9 \\
\hline Normal & 57160 & 3119 & 60279 & 68,0 & 25,6 & 62,6 \\
\hline Total & 84045 & 12197 & 96242 & 100,0 & 100,0 & 100,0 \\
\hline
\end{tabular}

Fuente: Procesamiento especial de las bases de microdatos censales.

a Excluye a las mujeres con condición de maternidad desconocida.

GRÁFICO 10

Chile: Mujeres de 17 años de edad con condición de maternidad conocida, por probabilidad de estar estudiando según trayectoria educativa y condición de maternidad, 2002

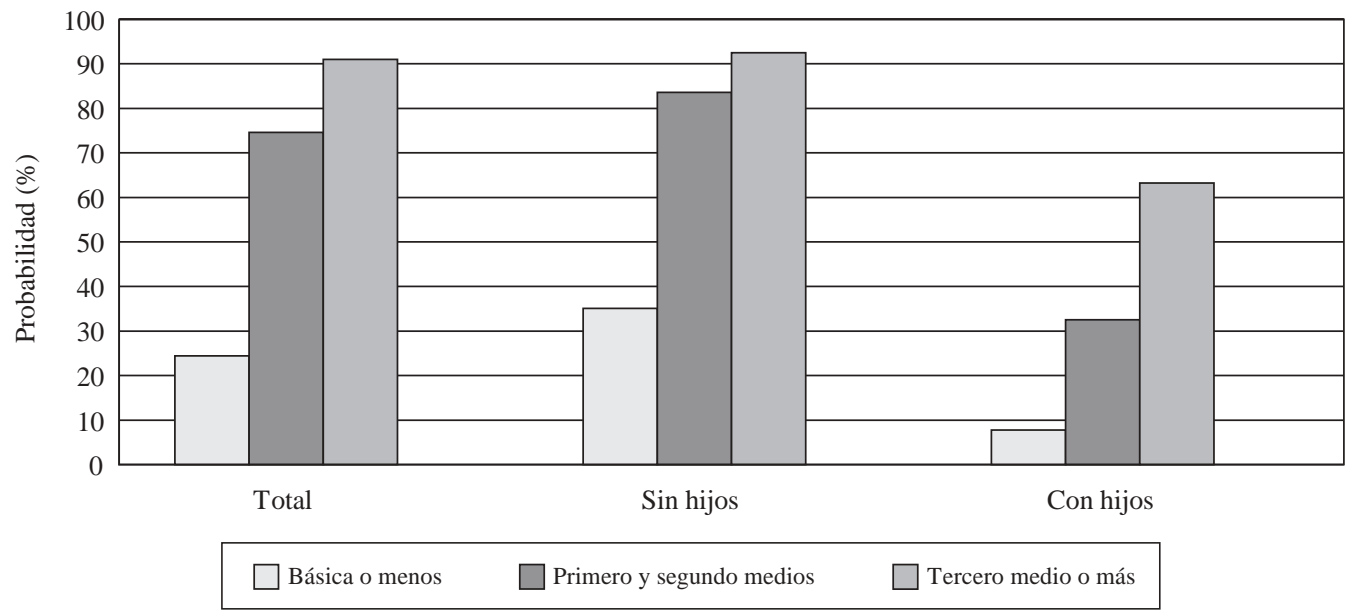

Fuente: Procesamiento especial de las bases de microdatos censales.

17 años la trayectoria normal duplica la probabilidad de permanecer en la escuela respecto de la trayectoria atrasada y la multiplica por siete respecto de la trayectoria rezagada (véase gráfico 10 ).

Por último, el gráfico 11 completa el panorama sobre la relación entre trayectoria educativa, actividad y maternidad adolescente: la maternidad con una trayectoria educativa rezagada no predispone a una mayor participación laboral, sino que conduce básicamente a la dedicación doméstica, probablemente en tareas relacionadas con la crianza. Este último hallazgo no coincide con estudios previos, como el de Buvinic (1998), y revela la acumulación de desventajas que afectan a las muchachas pobres, para quienes la ma- ternidad coincide con deserción escolar y marginación del mercado de trabajo.

Cabe mencionar dos resultados relevantes: i) mientras el grueso de las mujeres de 17 años ya completó el tercero medio y probablemente se encuentra cursando el cuarto medio o niveles superiores incluso, el $57 \%$ de las madres ${ }^{16}$ no ha completado el segundo medio, siendo la frecuencia modal el octavo básico; es decir,

\footnotetext{
16 Exactamente el $57 \%$ de ellas tiene primero medio (valor de variable escolaridad igual a 9) o menos educación completada. Se proporciona el dato porque el gráfíco 11 no permite una conclusión visual directa al respecto.
} 
GRÁFICO 11

Chile: Mujeres de 17 años, por actividad principal, según trayectoria educativa y condición de maternidad, 2002

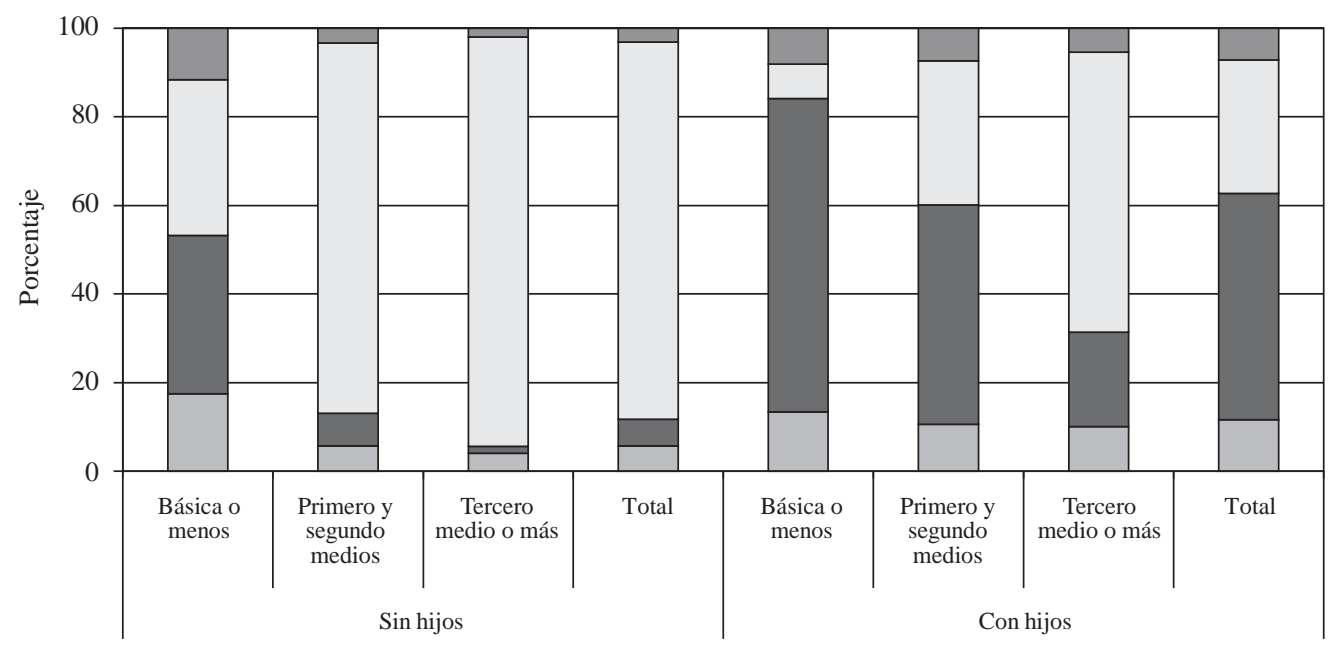

$$
\square \text { PEA } \square \text { En la casa } \square \text { Estudia } \square \text { Otra }
$$

Fuente: Procesamiento especial de las bases de microdatos censales.

GRÁFICO 12

Chile, mujeres de 17 años de edad: Cantidad de mujeres y de madres según años de escolaridad, y porcentaje de madres según años de escolaridad, $2002^{\mathrm{a}}$

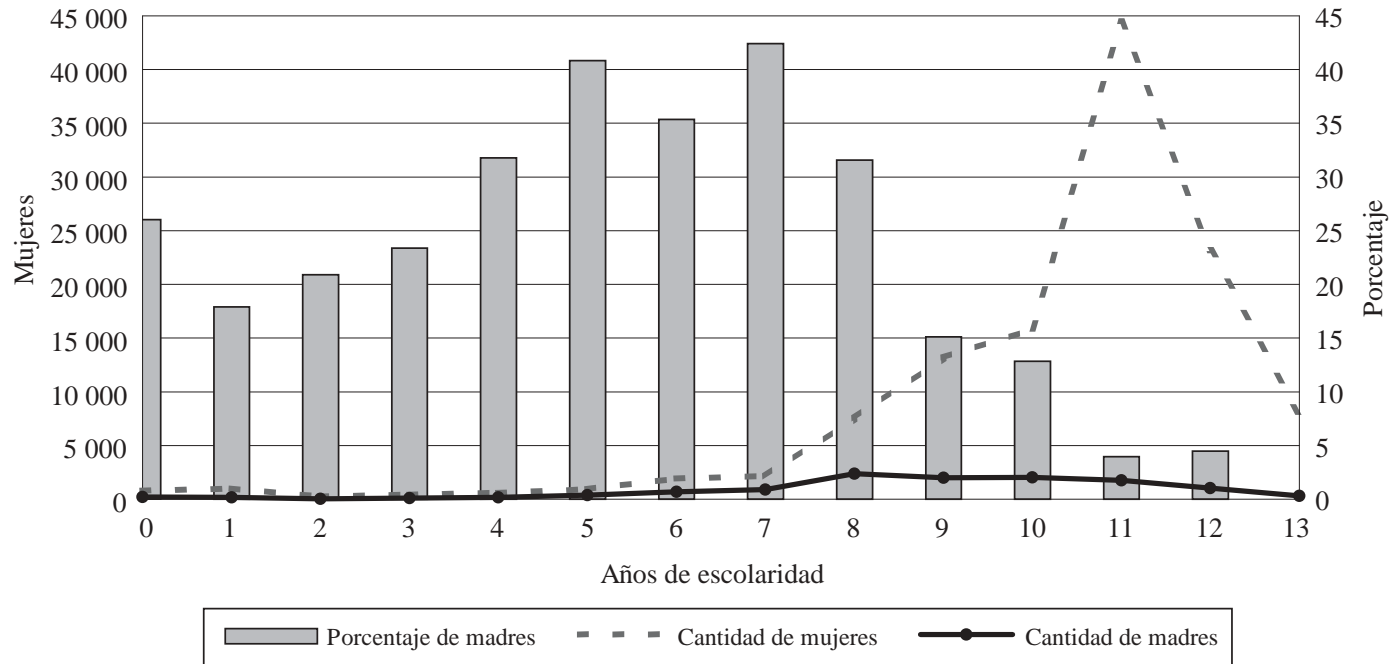

Fuente: Procesamiento especial de las bases de microdatos censales.

a La probabilidad considera a todas las mujeres, es decir imputa cero hijos a las que no respondieron la pregunta por hijos nacidos vivos. Las tendencias no cambian si se considera solo a las mujeres que respondieron. 
las madres adolescentes tienen una escolaridad menor al promedio, pero están lejos de carecer de educación o de tener mínima educación; ii) la probabilidad de haber sido madre a los 17 años está estrechamente asociada a la escolaridad alcanzada por las muchachas, pero esta relación no es lineal ya que cabe distinguir tres grupos: las que no han llegado a completar cuarto básico con una probabilidad de $26 \%$ o menos; las que tienen entre cuarto y octavo básicos rendidos con probabilidades de $30 \%$ o más (llegando a 42,4\% entre las que alcanzaron a completar solo hasta séptimo básico); y las que han enterado el primero medio (nueve años de escolaridad) o han terminado niveles superiores, para las cuales la probabilidad es de $15 \%$ o menos, llegando a guarismos inferiores al $5 \%$ para las que completaron tercero medio o se encuentran en niveles de escolaridad más elevados aún (véase el gráfico 12). Así, se puede concluir que, no obstante la persistente e indiscutible asociación entre una mayor educación y una menor probabilidad de ser madre adolescente, hay signos de que la acumulación de escolaridad no tiene un efecto protector continuo contra la maternidad precoz, ya que las muchachas que completaron entre cuatro y ocho años de escolaridad a la edad de 17 años están más expuestas a ser madres precoces que las de menor escolaridad. Es decir, debe sobrepasarse un umbral de acumulación de escolaridad para que la protección contra el embarazo se active. Este último hallazgo debe ser leído con cautela, pues las muchachas con menos de cuatro años de educación terminados son pocas y hay indicios de que una parte de ellas corresponde a casos especiales de truncamiento de la trayectoria educativa vinculados simultáneamente con una menor probabilidad de ser madre (enfermedades y/o accidentes invalidantes, retrasos severos de aprendizaje, etc.).

\section{VI}

\section{Pobreza y maternidad adolescente: continuidad y cambio de una relación histórica}

La probabilidad de ser madre a edad temprana no se distribuye de manera aleatoria entre los grupos socioeconómicos, pues es más alta entre los grupos pobres, excluidos o socialmente desaventajados. Usando como variable de estratificación socioeconómica un índice de equipamiento simple que permite segmentar los hogares en terciles socioeconómicos específicos para zonas urbanas y rurales, se verifica que en los ámbitos considerados las muchachas del tercil inferior registran probabilidades mucho mayores de haber sido madre en todas las edades de la adolescencia. Aproximadamente el $50 \%$ de las mujeres del tercil socioeconómico inferior del campo tienen su primer hijo antes de cumplir los 20 años, mientras que tal situación afecta a menos del $15 \%$ de las muchachas del tercil alto urbano. Cabe destacar que las brechas están moderadas por el hecho de usar como categoría socioeconómica los terciles del índice de equipamiento. Si la distinción hubiese sido la clásica entre indigentes, pobres y no pobres (CEPAL, 1998), la disparidad habría sido mayor.

Cabe destacar que esta diferencia en materia de fecundidad adolescente se da pese a que la fecundidad total en Chile ha tendido a la convergencia entre gru- pos socioeconómicos. Según estimaciones indirectas efectuadas con el procedimiento P/F de Brass en 2002, las mujeres sin educación exhibían una tasa global de fecundidad de 2,5 hijos; las que contaban con 1 a 8 años de escolaridad tenían una TGF de 2,8 hijos; las que tenían entre 9 y 12 años de escolaridad llegaban a una TGF de 2,5 hijos y, finalmente, las mujeres con 13 o más años de escolaridad registraban una TGF de 1,8 hijos. ${ }^{17} \mathrm{El}$ cotejo de los gráficos 13 y 14 , por el contrario, sugiere que las desigualdades entre grupos sociales en materia de maternidad adolescente se han mantenido prácticamente constantes entre 1992 y 2002; considerando sólo la edad de 19 años, cuyo guarismo es el que más se aproxima a la probabilidad de ser madres durante la adolescencia, se advierte un ligero descenso en el tercil bajo (del 40\% en 1992 al 37\% en 2002), una ligera alza en el tercil medio (del $25 \%$ en 1992 al 27\% en 2002) y una pequeña elevación en el

\footnotetext{
17 Estas diferencias eran mucho más abultadas en 1982, cuando las TGF eran de 4,1, de 3,7, de 2,5 y de 2,1 respectivamente (cálculos sobre microdatos censales, usando la estimación indirecta P/F de Brass).
} 


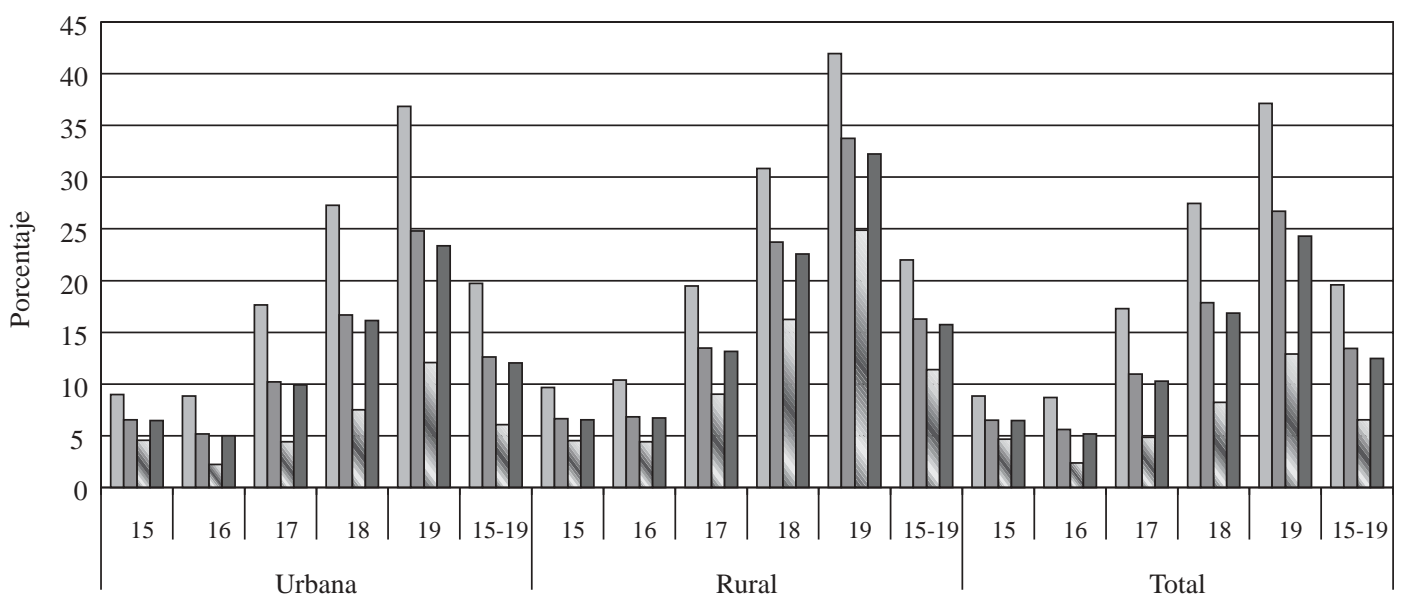

$\square$ Bajo $\square$ Medio $\square$ Alto $\square$ Total

Fuente: Procesamiento especial de las bases de microdatos censales.

GRÁFICO 14

Chile: Mujeres de 15 a 19 años de edad, por edad simple y probabilidad de haber sido madre, según tercil socioeconómico y zona de residencia, 1992

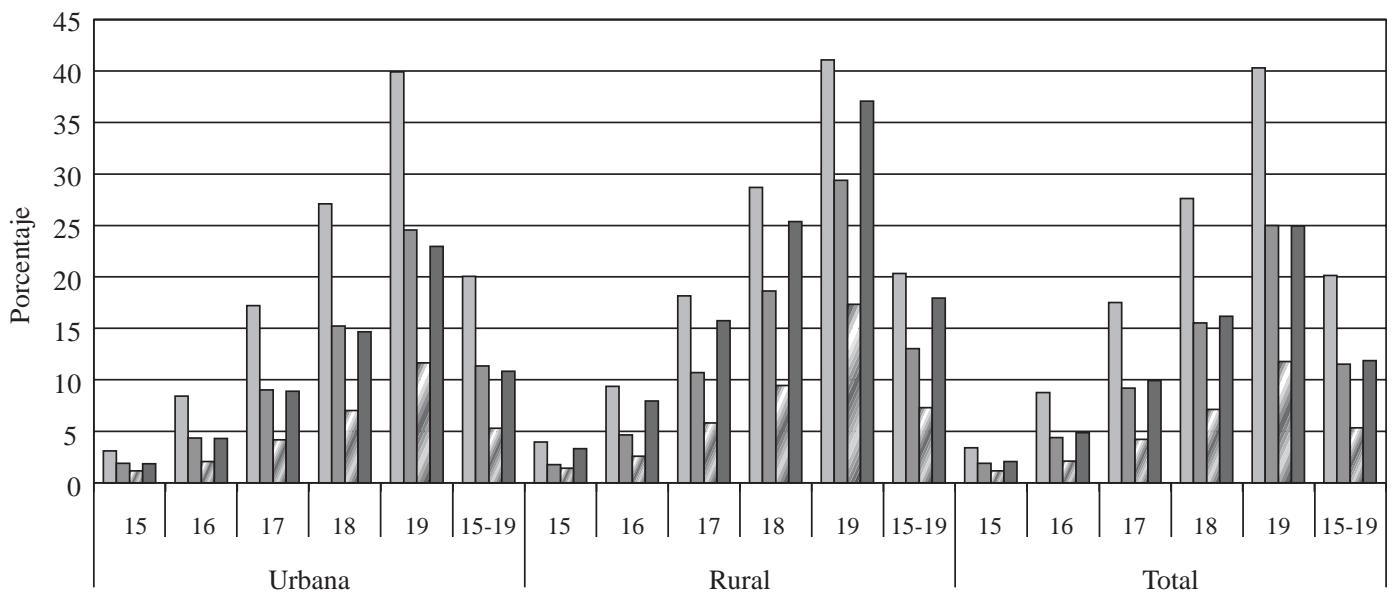

$\square$ Bajo $\square$ Medio $\square$ Alto $\square$ Total

Fuente: Procesamiento especial de las bases de microdatos censales.

tercil alto (del 11\% en 1992 al 13\% en 2002). En suma, mientras las disparidades entre grupos socioeconómicos se han atenuado en materia de intensidad reproductiva, no lo han hecho en términos del calendario de la fecundidad, que sigue siendo mucho más temprano entre las muchachas pobres. 


\section{VII}

\section{Acerca de los determinantes de la fecundidad adolescente: una primera aproximación}

Los factores que influyen sobre la probabilidad de ser madre adolescente tienen indiscutibles dimensiones socioeconómicas: son la pobreza, la exclusión y la falta de opciones. Estos interactúan con otros factores para configurar tanto las conductas reproductivas específicas de cada adolescente como las tendencias agregadas que se forman con los comportamientos individuales. Entre estos otros factores cabe distinguir:

a) los sicológicos, es decir rasgos de personalidad respecto de los cuales las encuestas y censos indagan poco o nada, de manera que sobre su actuación a gran escala hay lagunas de información;

b) los individuales, es decir, los atributos personales adquiridos en el proceso de socialización y que inciden en las conductas, como la religiosidad;

c) los familiares, que atañen al contexto doméstico en el que se desenvuelven las muchachas y los muchachos y que influyen sobre ellos por los modelos de conducta que se despliegan, los límites que se definen, las normas que se proporcionan y los controles que se ejercen;

d) los culturales, que tienen varias facetas: i) el tradicionalismo que se asocia a la maternidad adolescente, porque promueve y/o acepta la unión temprana; ii) la marginalidad, quizá directamente vinculada con la exclusión y la pobreza antes mencionadas, y que tiende a hacer más frecuente la reproducción durante la adolescencia por una sexualidad precoz en el marco de una escasa supervisión (de los padres, institucional o de salud) y por la ausencia de opciones alternativas a la maternidad temprana, y iii) la tolerancia sexual, específicamente en términos de iniciación sexual prematrimonial (aunque no forzosamente iniciación más precoz), que si no va asociada a una mayor tolerancia y acceso a medios anticonceptivos (modernidad sexual truncada) puede favorecer la maternidad entre las adolescentes;

e) los políticos e institucionales, en particular los programas, organismos, intervenciones, leyes y marcos normativos que actúan sobre los adolescentes o que definen comportamientos permitidos para ellos, y f) los medios de comunicación masivos, cuyos mensajes sobre el erotismo, la afectividad y la sexualidad influyen poderosamente en los muchachos y las muchachas.

Desentrañar cómo operan estos factores en los comportamientos individuales es una tarea pendiente que desborda los límites de este artículo. Cualquiera sea el caso, se trata de determinantes de última instancia, pues como ha establecido el denominado "esquema de las variables intermedias de la fecundidad" (Bay, del Popolo y Ferrando, 2003; Bongaarts, 1978), hay un conjunto de "determinantes próximos de la fecundidad" que son los que directamente definen la probabilidad de tener un hijo y las tendencias agregadas de la fecundidad. Estos determinantes próximos se relacionan con las condiciones biológicas (etapa fértil de la vida, esterilidad total o transitoria, como suele ocurrir durante la lactancia, propensión a embarazos múltiples, etc.), con los comportamientos sexuales (iniciación, regularidad, abstinencia total o por períodos debido a razones culturales, etc.) que históricamente han estado muy ligados a las pautas de formación y disolución de uniones, con las prácticas anticonceptivas (iniciación, regularidad, eficiencia y tipo de método) y con la frecuencia del aborto espontáneo e inducido.

La fecundidad adolescente es afectada directamente por cinco determinantes próximos: i) la edad de la menarquia, ii) los índices de infertilidad, iii) los patrones de iniciación y de actividad sexuales, iv) los patrones de uso de anticonceptivos y v) los índices de aborto espontáneo o inducido. En general, los dos primeros no son considerados porque no contribuyen mucho a explicar diferencias transversales (entre grupos socioeconómicos) o longitudinales (evolución en el tiempo) de la fecundidad. El tercero suele ser remplazado por los patrones de unión, en el entendido de que esta información es más fácil de obtener. Los dos determinantes finales tienen una importancia crucial, sobre todo porque tienden a imponerse al resto en las sociedades contemporáneas. Vale decir, cuando la cobertura de anticoncepción eficiente es alta, regular y temprana, la mayor parte de las parejas logra tener el número de hijos que desea. Por lo tanto, 
las causas directas de la resistencia al descenso de la fecundidad adolescente en Chile han de encontrarse en la evolución de estos determinantes próximos. Lamentablemente, no hay una fuente de información única, confiable e idónea para captarlos; más aún, sobre algunos (como el aborto inducido) no hay estimaciones confiables por tratarse, bajo cualquier circunstancia, de un delito según la legislación chilena vigente.

Con todo, hay algunos indicios que permiten dar algo más de claridad a la situación. Primero, Chile no tendría por qué sustraerse a una tendencia secular hacia el adelantamiento de la menarquia e incremento de la capacidad biológica de reproducción de las adolescentes (Silber y Castells, 2003, p. 24); sin embargo, por la escasa cuantía de los nacimientos antes de los 15 años de la madre, esta tendencia difícilmente explica la evolución de la maternidad adolescente. Segundo, el patrón de unión muestra signos de retraso, lo que ciertamente le resta relevancia como factor explicativo de las tendencias de la fecundidad adolescente, pues en virtud de esta postergación la fecundidad adolescente debiera estar descendiendo. Tercero, los pocos estudios de alcance nacional sobre conductas sexuales y anticonceptivas sugieren que: i) en los últimos 60 años ha habido una relativa estabilidad de la iniciación sexual — cuya mediana para las mujeres se ha movido entre los 21,3 años de edad (cohorte nacida entre 1944 y 1948) y los 18 años de edad (cohorte nacida entre 1979 y 1980)—, aunque las generaciones más jóvenes parecen estar iniciándose más temprano (CONASIDA, 2000, pp. 154-158; INJuv, s/f, p. 13); ii) los hombres típicamente declaran una iniciación sexual más temprana, aunque las disparidades en este plano han tendido a disminuir (INJUv, s/f, pp. 16 y 17); iii) hay un aumento importante de la proporción de muchachos y muchachas que toma precauciones anticonceptivas en su iniciación sexual, ya que así lo hizo una de cada cuatro mujeres con experiencia sexual de 18 a 24 años en el 2000, frente a solo seis de cada 100 mujeres de 45 a 69 años de edad en el 2000; iv) pese a esta alza, el uso de anticonceptivos entre las adolescentes sigue siendo bajo, pues la mayoría está expuesta al embarazo.

En suma, el adelantamiento de la iniciación sexual parece contrarrestar el alza de los niveles de precaución anticonceptiva en la primera unión. Más aún, esta cifra no permite estimar si la precaución anticonceptiva es regular una vez iniciada la vida sexual ni tampoco si es llevada a cabo de manera prolija o eficiente. Datos recientes indican que casi un 35\% de las personas de 15 a 19 años de edad en 2003 no usó protección anticonceptiva en su última relación sexual y que un $6 \%$ usó formas inseguras como el coitus interruptus

Iberoamérica: Porcentaje de muchachas que usó anticonceptivos modernos en su primera relación sexual, ${ }^{\mathrm{a}}$ en fechas entre 1991 y 2000

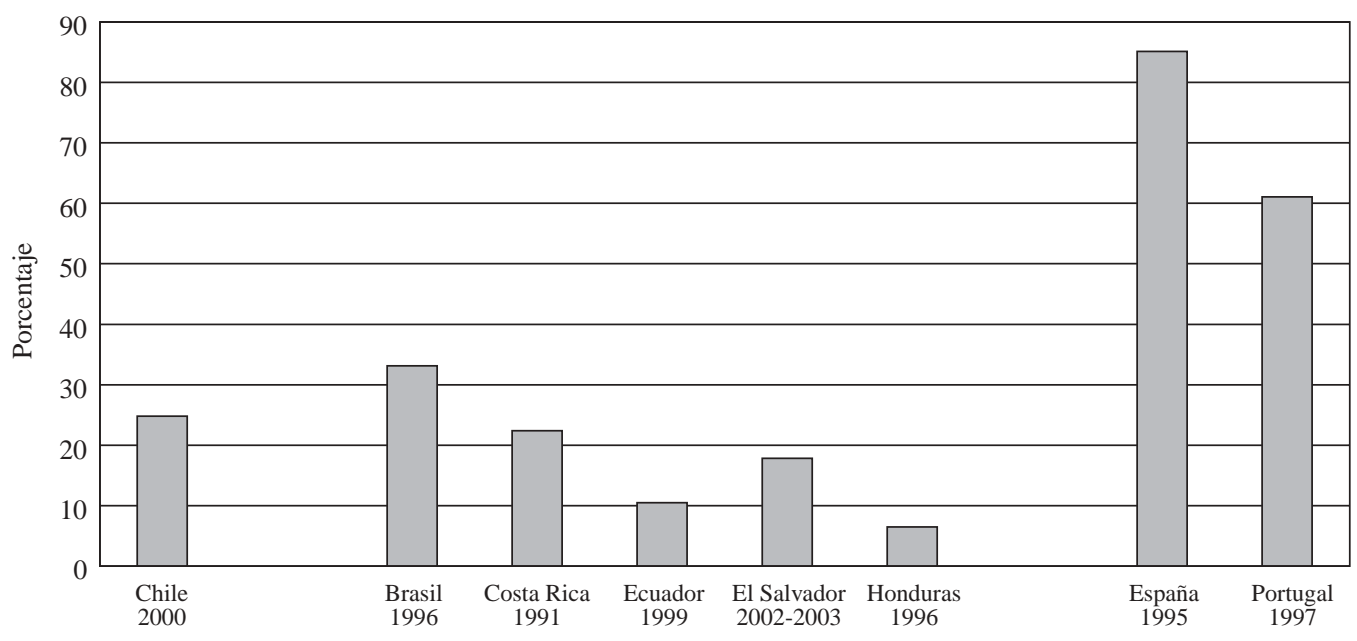

Fuente: Para España y Portugal: Naciones Unidas, Encuestas de Fertilidad y Familia, varios años. Para los países latinoamericanos (salvo Chile y El Salvador): CEPEP/USAID/CDC (1999, p. 72, cuadro 7.13). Para El Salvador: ADS/CDC (2003, p. 200, cuadro 9.12). Para Chile: CONASIDA (2000, p. 158).

a En España corresponde al grupo de 18 y 19 años, en Portugal al de 20 a 24 años, en Chile al grupo de 18 a 24 años y en el resto de los países latinoamericanos al de 15 a 24 años. 
(INJUV, s/f, pp. 16 y 17). Esta tensión entre una sexualidad que se adelanta y un acceso a medios anticonceptivos que no se extiende con la misma fuerza y regularidad entre los y las adolescentes (gráfico 15), es la base de sustentación de los persistentes índices de maternidad adolescente expuestos en este estudio.

Ahora bien, a diferencia de lo que acontece con las tendencias generales de la reproducción durante la adolescencia, los patrones de unión sí parecen tener un efecto en las disparidades socioeconómicas de la maternidad adolescente. En efecto, la evidencia censal sugiere que históricamente las muchachas de estrato bajo han tenido una tendencia a unirse (casarse o convivir) más temprano, lo que favorece la reproducción más precoz (CEPAL/OIJ, 2003). Con todo, la alta y creciente frecuencia de la maternidad al margen de una unión sugiere que el principal factor de diferencia entre los grupos socioeconómicos estriba en su conducta sexual y anticonceptiva. Aunque los antecedentes empíricos al respecto no son sistemáticos, la encuesta levantada por CONASIDA en el 2000 muestra que la iniciación sexual es más temprana entre las muchachas con menos educación y/o pertenecientes a estratos bajos; así, el grupo de nivel socioeconómico medio alto registra una mediana de iniciación de 19,4 contra 17,9 del grupo de nivel socioeconómico bajo (CONASIDA, 2000 , p. 161). Lamentablemente, la publicación citada no ofrece información sobre desigualdades sociales en materia de uso de anticoncepción y menos de utilización del aborto; sin embargo, por las características de la provisión de anticonceptivos en Chile, es probable que la prevalencia entre adolescentes sexualmente activas sea más baja en los grupos de menor nivel socioeconómico.

\section{VIII}

\section{Análisis final: insumos de política}

Por todo lo expuesto anteriormente - la maternidad adolescente refractaria al descenso; el aumento de la maternidad adolescente en condiciones de soltería, la probabilidad mucho más elevada de que las madres adolescentes estén al margen del sistema escolar y dedicadas básicamente a tareas domésticas; la transferencia de responsabilidades de crianza a los progenitores de las muchachas, y la probabilidad mucho más alta que tienen las adolescentes pobres de ser madres antes de los 20 años - no hay duda de que el embarazo y la maternidad adolescentes han de estar entre los temas prioritarios de la agenda social y ameritan varios programas públicos coordinados. Más aún, la persistencia de una fecundidad adolescente elevada puede incluso erosionar las holguras derivadas de la baja de la fecundidad total. En este sentido, es importante para la formulación de políticas comprobar que la reproducción durante la adolescencia no muestra los patrones usuales de relación con las variables intermedias. Esta realidad ratifica el llamamiento del Programa de Acción de la Conferencia Internacional sobre la Población y el Desarrollo a que los gobiernos, en colaboración con las organizaciones no gubernamentales, "atiendan las necesidades especiales de los adolescentes y establezcan programas apropiados para responder a ellas" (http://www.unfpa.org/spanish/icpd/ icpd_poa.htm\#ch7e), y exige un esfuerzo tendiente a concebir y poner en práctica medidas que reconozcan las peculiaridades de los y las adolescentes, sobre todo en el plano de sus conductas sexuales, de pareja y de autocuidado y protección.

Una segunda constatación relevante para la formulación de políticas deriva de la distinción entre al menos dos modalidades reproductivas durante la adolescencia. La más tradicional tiene un anclaje cultural difícil de remover; sin embargo, las medidas destinadas a promover el aplazamiento de la unión y, sobre todo, a ampliar la cobertura de servicios de salud sexual y reproductiva entre las muchachas unidas (en el entendido que la procreación en estos contextos se da en el marco de las uniones) pueden dar resultados tanto en el calendario como en la intensidad de la fecundidad. Por su parte, la modalidad reproductiva vinculada a lo que aquí se ha llamado "modernidad truncada" amerita intervenciones rápidas y amplias. Las más directas atañen a la educación y el fomento de conductas responsables, tanto para postergar la iniciación sexual como para tomar precauciones anticonceptivas desde su misma iniciación. Ahora bien, para lograr esto último la mera educación no basta; es necesario acercar a los adolescentes servicios de consejería, de apoyo especializado y de distribución de anticonceptivos (y enseñanza para su uso regular y adecuado). 
Un tercer aporte de este trabajo a la formulación de políticas es la actualización del papel de la escuela y la educación en general en lo que se refiere a la reproducción durante la adolescencia. Surge como hallazgo una cierta desvalorización de la educación en tanto factor que protege frente a la maternidad adolescente. A escala agregada, esto se vincula a la independencia entre la evolución de la maternidad adolescente (estable o ligeramente al alza en los últimos 20 años) y la escolaridad media de los y las adolescentes (que aumentó bastante en dicho período). Y a escala individual se traduce en que las mayores probabilidades de ser madre adolescente no se dan entre las muchachas de menor educación sino entre aquellas que tienen 5 a 7 años de estudio. Pese a ello, la principal conclusión de política del estudio es que una trayectoria educativa "normal" que permita completar el ciclo secundario a los 17 o 18 años actúa como blindaje poderoso, aunque no infalible, contra la maternidad adolescente; más aún, tal trayectoria normal aumenta de manera importante las probabilidades de que la muchacha siga asistiendo a la escuela después del parto. En suma, evitar la salida anticipada de la escuela se convierte en un objetivo múltiple de política.

Los aportes que hemos señalado ponen de relieve al menos seis ámbitos de acción. El primero es el ámbito público y tiene que ver con las disposiciones administrativas y legales generales que limitan el acceso de los adolescentes al conocimiento y al uso adecuado de medios anticonceptivos. La experiencia comparada, en particular el caso de Europa occidental, sugiere que el principal recurso para lograr niveles bajos de reproducción durante la adolescencia es el acceso a anticonceptivos desde el inicio de la vida sexual y la formación para su uso regular, responsable y eficiente. En tal sentido, resulta paradójico que en muchos países de la región se tienda a rebajar los umbrales etarios para imputar responsabilidades, por ejemplo en materia penal, y se mantenga límites más elevados de edad para la compra o prestación de medios anticonceptivos. Ahora bien, la experiencia latinoamericana alerta respecto de las debilidades de una expansión exclusivamente formal del acceso a estos medios. Para que ese acceso dé resultado, debe operar antes de que los adolescentes se unan o tengan su primera relación sexual - lo que se contrapone a la práctica de aceptar adolescentes en los programas de planificación familiar sólo si están unidas o ya tuvieron un hijo- y debe ir acompañado de reforzamientos de distinto tipo, en particular para el ejercicio de conductas responsables en materia sexual.
El segundo ámbito es el cultural y tiene que ver con la disonancia entre discursos significativos para los muchachos y las muchachas (de instituciones y de sus mayores) que eluden o niegan la realidad de la sexualidad adolescente, por una parte, y su exposición constante y creciente a imágenes, símbolos y estímulos para la actividad sexual temprana, por otra. Así, junto a la necesaria protección normativa que requieren los púberes y adolescentes frente a las inducciones, presiones y agresiones de los adultos, en particular en materia sexual, y la imprescindible formación de una capacidad de decisión responsable, es fundamental la puesta al día de los imaginarios oficiales y familiares. La visión de los y las adolescentes en soltería (que son la mayor parte, según se ha mostrado) como sujetos inhabilitados para la actividad sexual y por ende ajenos a la necesidad de medios anticonceptivos, resulta abiertamente contradictoria con la realidad y choca con la cotidianidad juvenil, repleta de símbolos y alegorías sexuales.

El tercer ámbito es el sectorial, particularmente el de la salud, donde todavía se niega un trato y un acercamiento especial a los y las adolescentes, por lo cual muchos de ellos se mantienen alejados de tales servicios. Como ya se ha subrayado, para el acercamiento de los muchachos y muchachas a los servicios de salud es preciso brindarles espacios con cierta autonomía para su atención, incluso en el marco de enfoques integrales de atención de la salud.

El cuarto ámbito es la escuela, que ofrece una amplia variedad de mecanismos de protección ante la maternidad adolescente. Algunos de esos mecanismos parecen provenir, hasta ahora, del mero hecho de "estar allî" y ocupar el tiempo en una actividad que ordena la cotidianidad, que disciplina y que concentra esfuerzos, lo que añade una externalidad positiva a los programas de retención escolar hasta la finalización del ciclo secundario. Otros derivan de las capacidades que brinda la educación en materia de conocimiento y uso de precauciones anticonceptivas, manejo de los impulsos y formación técnica y afectiva sobre asuntos de sexualidad y reproducción. Y otros, sin duda, son aquellos asociados con las expectativas y horizontes que abre la acumulación de educación, ya sea para el trabajo o la continuidad de estudios en un nivel superior. Con todo, el papel indiscutiblemente "protector" de la escuela en materia de embarazo adolescente no debe considerarse garantizado. Este espacio, como cualquier otro, permite la interacción y los encuentros sexuales entre muchachos y muchachas, y tiende a promover estilos de vida con frecuencia más tolerantes frente al 
sexo, por lo que debe considerar una formación especial en materia de sexualidad informada y responsable; además, si la educación secundaria se devalúa como factor de movilidad social, su capacidad de ser una alternativa real al embarazo adolescente se debilita.

Los dos últimos espacios tienen que ver con el círculo más directo de los y las adolescentes, a saber, la familia y la pareja. La familia tiene una enorme influencia sobre la conducta de los muchachos y las muchachas y es un canal principal para su formación y habilitación como sujetos responsables. Cuando las familias instruyen y preparan adecuadamente a su prole es mucho más probable que las conductas sexuales estén signadas por la responsabilidad. En algunos ca- sos esta responsabilidad puede llevar a que se postergue la primera relación sexual, mientras que en otros significará adoptar precauciones para evitar problemas de salud y embarazos no deseados. Con todo, no puede dejar de reconocerse que en muchos casos no hay sintonía entre la familia y el adolescente (porque la familia no se preocupa, porque opera con principios que el adolescente no comparte o porque idealiza la conducta del hijo/hija) y en esas circunstancias, tarde o temprano, es el adolescente el que debe adoptar las decisiones. Por último, respecto de la pareja, la capacidad de negociación y de compartir responsabilidades es uno de los terrenos más propicios para promover conductas sexuales y reproductivas responsables.
ADS/CDC (Asociación Demográfica Salvadoreña/Centros para el Control y la Prevención de Enfermedades) (2003): Encuesta Nacional de Salud Familiar: FESAL 2002/03, San Salvador.

Bay, G., F. del Popolo y D. Ferrando (2003): Determinantes próximos de la fecundidad: una aplicación a países latinoamericanos, serie Población y desarrollo, $\mathrm{N}^{\circ}$ 43, LC/L.1953-P; LC/L.1953-P/Corr.1-P, Santiago de Chile. Publicación de las Naciones Unidas, $\mathrm{N}^{\mathrm{o}}$ de venta: S.03.II.G.21.

Bongaarts, J. (1978): A framework for analyzing the proximate determinants of fertility, Population and Development Review, vol. 4, No 1, Nueva York, Consejo de Población.

Buvinic, M. (1998): Costos de la maternidad adolescente en Barbados, Chile, Guatemala y México, Informe técnico, No WID-102, Washington, D.C., Banco Interamericano de Desarrollo.

CEPAL (Comisión Económica para América Latina y el Caribe) (1998): Panorama social de América Latina, 1997, LC/G.1982-P, Santiago de Chile. Publicación de las Naciones Unidas, $\mathrm{N}^{\circ}$ de venta: S.98.II.G.3.

CEPAL/CELADE (Comisión Económica para América Latina y el Caribe/Centro Latinoamericano y Caribeño de Demografía (CELADE) (2002): Vulnerabilidad sociodemográfica: viejos y nuevos riesgos para comunidades, hogares y personas, LC/G.2170(SES.29/16), Santiago de Chile.

(2004): La fecundidad en América Latina: itransición o revolución?, serie Seminarios y conferencias, $\mathrm{N}^{\mathrm{o}} 36$, LC/L.2097-P, Santiago de Chile. Publicación de las Naciones Unidas, $\mathrm{N}^{\mathrm{o}}$ de venta: S.04.II.G.34.

CEPAL/OIJ (Comisión Económica para América Latina y el Caribe/ Organización Iberoamericana de la Juventud) (2003): Juventud e inclusión social en Iberoamérica, LC/R.2108, Santiago de Chile.

(2004): La juventud en Iberoamérica: tendencias y urgencias, LC/L.2180, Santiago de Chile.

CEPEP/USAID/CDC (Centro Paraguayo de Estudios de Población/ Agencia de los Estados Unidos para el Desarrollo Internacional/Centros para el Control y la Prevención de Enfermedades) (1999): Encuesta Nacional de Salud Materno Infantil, 1998 (ENSMI-98). Informe final, Asunción.

CONASIDA (Comisión Nacional del Sida) (2000): Estudio nacional de comportamiento sexual: primeros análisis. Chile 2000, Santiago de Chile, Ministerio de Salud.

Donoso, E., J. Becker y L. Villarroel (2003): Natalidad y riesgo reproductivo en adolescentes de Chile, 19901999, Revista panamericana de salud pública, vol. 14, № 1, Washington, D.C., Organización Panamericana de la Salud.

Dulanto, E. (2000): El adolescente, México, D.F., McGraw-Hill Interamericana.

Esping-Andersen, G. (1999): Social Foundation of Postindustrial Economies, Oxford, Reino Unido, Oxford University Press.

Flórez, C. y J. Núñez (2003): Teenage childbearing in Latin American countries, en S. Duryea, A. Cox y M. Ureta (comps.), Critical Decision at a Critical Age, Adolescents and Young Adults in Latin America, Washington, D.C., Banco Interamericano de Desarrollo.

Gage, A. (1995): The Social Implications of Adolescent Fertility, documento presentado en la Conferencia sobre demografía y pobreza (Florencia, Italia, 2 a 4 de marzo de 1995), Unión Internacional para el Estudio Científico de la Población.

Guzmán, J., R. Hakkert y otros (2001): Diagnóstico sobre salud sexual y reproductiva de adolescentes en América Latina y el Caribe, México, D.F., Fondo de Población de las Naciones Unidas (UNFPA).

INE (Instituto Nacional de Estadísticas) (2000): Fecundidad juvenil, Enfoques estadísticos, $\mathrm{N}^{\circ}$ 9, Santiago de Chile (www.sexualidadjoven.cl/estudios/enf_fecundidad.pdf).

(varios años): Anuario de Demografía, Santiago de Chile.

INJUV (Instituto Nacional de la Juventud) (s/f): La eventualidad de la inclusión: jóvenes chilenos a comienzos del nuevo siglo. Principales resultados: Tercera Encuesta Nacional de Juventud (http://www.injuv.gob.cl/cedoc_archivos/estudios/ Tercera_encuesta.pdf).

IPAS (2001): Jóvenes en riesgo: los adolescentes y la salud sexual, Notas informativas, Chapel Hill, enero, (www.ipas.org).

Lete, I., J. de Pablo y otros (2001): Embarazo en la adolescencia, en C. Buil, I. Lete y otros (coords.), Manual de salud reproductiva en la adolescencia: aspectos básicos y clínicos, Madrid, Sociedad Española de Contracepción [http:// ns.ccp.ucr.ac.cr/bvp/pdf/manual/saludreproductiva/].

Menkes, C. y L. Suárez (2003): Sexualidad y embarazo adolescente en México, Papeles de población, $\mathrm{N}^{\circ}$ 35, México, D.F., Universidad Autónoma del Estado de México.

Molina, M., C. Ferrada y otros (2004): Embarazo en la adolescencia y su relación con la deserción escolar, Revista médica de Chile, vol. 132, No 1, Santiago de Chile, Sociedad Médica de Chile. 
Molina, R., J. Sandoval y E. González (2003): Salud sexual y reproductiva en la adolescencia, Santiago de Chile, Mediterráneo.

Naciones Unidas (1986): Indirect Techniques for Demographic Estimation. Manual X, Nueva York, Population Studies, $N^{o}$ 81, ST/ESA/SER.A/81. Publicación de las Naciones Unidas, $\mathrm{N}^{\mathrm{o}}$ de venta: E.83.XIII.2.

Paz Ciudadana, Adimark y otros (2002): Deserción escolar en Chile, Santiago de Chile.

Rodríguez, J. (2004): La fecundidad en América Latina y el Caribe: un riesgo en transición, en CEPAL/CELADE, La fecundidad en América Latina: ¿transición o revolución?, serie Seminarios y conferencias, $\mathrm{N}^{\mathrm{o}}$ 36, LC/L.2097-P, Santiago de Chile. Publicación de las Naciones Unidas, $\mathrm{N}^{\mathrm{o}}$ de venta: S.04.II.G.34 SERNAM (Servicio Nacional de la Mujer) (2004): Mujeres chilenas: tendencias en la última década, Santiago de Chile, Departamento de Estudios y Estadísticas.

Silber, T. y P. Castells (2003): Guía práctica de la salud y psicología del adolescente, Barcelona, Planeta.

Singh, S. (2000): Diferencias según sexo en el momento de la primera relación sexual: datos de 14 países, Perspectivas internacionales en planificación familiar, número especial, México, D.F., Instituto Nacional de Salud Pública. 